\title{
NMDA receptors enhance the fidelity of synaptic integration
}

\author{
Chenguang Li, Arielle L. Baker, and Allan T. Gulledge* \\ Department of Molecular and Systems Biology, \\ Geisel School of Medicine at Dartmouth \\ 74 College Street, Vail 601 \\ Hanover, NH 03755, USA
}

${ }^{*}$ Correspondence: allan@dartmouth.edu

\section{Key points}

- Excitatory neurotransmission at many central synapses is mediated by two co-expressed ionotropic glutamate receptors, AMPA and NMDA receptors, that differ in their kinetics and voltage-sensitivities.

- Using computational simulations, we show that the combined synaptic presence of AMPA and NMDA receptors enhances the fidelity of somatic responses to spatiotemporal patterns of excitatory synaptic input generated at different initial membrane potentials and/or at different dendrite domains.

- This effect, which was robust across a wide range of AMPA-to-NMDA ratios, reflects enhanced NMDA currents occurring at depolarized membrane potentials that are preferentially attained in distal, highimpedance dendritic compartments.

- Thus, the intrinsic voltage-sensitivity of NMDA receptors conveys distinct advantages for synaptic integration (e.g., stability of EPSP spike coupling across spatial and voltage domains) that are independent of, but fully compatible with, their well-established importance for coincidence detection and synaptic plasticity.

Abstract In many central neurons, excitatory synaptic transmission is mediated by two co-expressed ionotropic glutamate receptor subtypes, AMPA and NMDA receptors, that differ in kinetics, ion-selectivity, and voltage-sensitivity. AMPA receptors have fast kinetics and are voltage-insensitive, while NMDA receptors have slower kinetics and exhibit larger conductance at depolarized membrane potentials. Here we report that the voltage-dependency of NMDA receptors intrinsically stabilizes synaptic integration of excitatory postsynaptic potentials (EPSPs) across both spatial and voltage domains. Using computational simulations of synaptic integration in simplified and morphologically realistic dendritic trees, as well as physiological measurements in ex-vivo cortical neurons from male and female mice, we show that NMDA conductances reduce the variability of somatic responses to spatiotemporal patterns of excitatory synaptic input presented at different membrane potentials and/or dendritic domains. The moderating effect of NMDA conductance on synaptic integration was robust across a wide range of AMPA-to-NMDA ratios, and reflects enhanced NMDA currents occurring at depolarized membrane potentials that are preferentially attained in distal, high-impedance dendritic compartments. The added NMDA current acts to balance voltagedependent changes in synaptic driving force and distance-dependent attenuation of synaptic potentials arriving at the axon, thereby increasing the fidelity of synaptic integration and EPSP-spike coupling across neuron state (i.e., initial membrane potential) and dendritic location. These results suggest that the intrinsic voltage-sensitivity of NMDA receptors conveys distinct advantages for synaptic integration that are independent of, but fully compatible with, their importance for coincidence detection and synaptic plasticity. 


\section{Introduction}

In the vertebrate central nervous system, fast excitatory synaptic transmission is mediated primarily by the amino acid glutamate, which at many synapses gates two coexpressed ionotropic receptors: $\alpha$-amino-3-hydroxy-5-methyl-4isoxazolepropionic acid (AMPA) and N-methyl-Daspartate (NMDA) receptors. While both receptor subtypes are gated by glutamate and permeable to monovalent cations, NMDA receptors exhibit slower kinetics, a permeability for calcium, and voltage-dependence due to channel blockade by extracellular magnesium ions at hyperpolarized membrane potentials (for review, see lacobucci \& Popescu, 2017). These features of NMDA receptors, which are highly conserved across phyla (Greer et al., 2017), are critical for their wellestablished role in gating associative synaptic plasticity, including certain types of long-term potentiation and depression (for review, see Luscher \& Malenka, 2012). NMDA receptors also influence synaptic integration, as the voltagedependence of NMDA receptors can promote linear (Cash \& Yuste, 1998) or supralinear (Schiller et al., 2000) summation of excitatory postsynaptic potentials (EPSPs) that occur in sufficient spatial and temporal proximity to relieve magnesium block of NMDA channels, and can reduce the voltagedependent variability of mixed AMPA/NMDA synaptic currents (Diamond \& Copenhagen, 1993; Connelly et al., 2016).

Because the input impedance of dendrites increases with distance from the soma, distal synapses generate larger, more depolarizing local dendritic EPSPs than do proximal synapses (Jaffe \& Carnevale, 1999; Gulledge et al., 2005). Yet the ability of an individual AMPA-mediated EPSP to recruit synaptic NMDA conductance is tempered by its rapid kinetics $(\sim 0.2$ and $2.0 \mathrm{~ms}$ activation and decay, respectively), which, when combined with the limited local capacitance of narrow dendrites, generates EPSPs that decay too rapidly to efficiently recruit slower activating (> $2 \mathrm{~ms}$ ) NMDA conductances (Stern et al., 1992; Gulledge et al., 2012). Instead, network-driven patterns of synaptic input interact within the dendritic tree based on their spatiotemporal relationships to recruit NMDA conductances (Polsky et al., 2009; Grienberger et al., 2014; Palmer et al., 2014; Cichon \& Gan, 2015), especially when they occur in highimpedance dendritic branches or spines (Branco \& Hausser, 2011; Gulledge et al., 2012; Harnett et al., 2012) and/or when barrages involve repetitive activation of the same synapses, as the extended occupancy of glutamate sites on NMDA receptors ( 100 ms) "prime" them for immediate gating during subsequent AMPA-mediated local depolarization (Schiller et al., 2000; Polsky et al., 2004). With sufficient levels of synaptic activation, inward NMDA currents become self-sustaining "NMDA spikes" that amplify and prolong synaptic depolarization to generate supralinear summative events at the soma and axon (for reviews, see Antic et al., 2010; Branco \& Hausser, 2010; Major et al., 2013; Grienberger et al., 2015).

We reasoned that the voltage-dependency of NMDA receptors, combined with the distancedependent electrotonic structure of dendritic trees, should reduce the variability of somatic drive (as measured as somatic depolarization and/or action potential generation) in response to identical spatiotemporal patterns of synaptic input occurring at different dendritic locations and/or from different initial membrane potential states. Here we test this hypothesis by simulating spatiotemporal patterns of synaptic input delivered at different dendritic locations and over a variety of membrane potential states, and by measuring optically evoked distributed EPSPs in neocortical pyramidal neurons before and after blockade of NMDA receptors. Together, our results reveal an intrinsic role for NMDA receptors in stabilizing synaptic integration and EPSP-spike coupling that is independent of, yet fully compatible with, their well-established roles in coincidence detection and synaptic plasticity.

\section{Materials and Methods}

\section{Ethical Approval}

Physiological experiments were approved by the Institutional Animal Care and Use Committee of Dartmouth College (protocol 2113) in accordance with the principles described by Grundy (2015).

\section{Computational models}

Simulations were made using NEURON 7.5 software (Carnevale \& Hines, 2006; RRID: SCR_005393) and the Neuroscience Gateway portal (Sivagnanam et al., 2013). Morphologies included "ball-and-stick" model neurons, consisting of somata connected to spinous dendrites of variable length and axons, a hippocampal CA3 pyramidal neuron (Hemond et al., 2009), a hippocampal dentate granule neuron (SchmidtHieber et al., 2007), and a layer 5 pyramidal neuron (Stuart \& Spruston, 1998). Table 1 lists the dimensions and membrane parameters for all neuron morphologies. Active mechanisms consisted primarily of fast-inactivating voltagegated sodium and delayed-rectifier potassium conductances (source codes available in ModelDB, entry 144385). In some simulations a 
bioRxiv preprint doi: https://doi.org/10.1101/566117; this version posted August 11,2019 . The copyright holder for this preprint (which was not certified by peer review) is the author/funder, who has granted bioRxiv a license to display the preprint in perpetuity. It is made available under

Table 1: Model parameters

\begin{tabular}{|c|c|c|c|c|}
\hline $\begin{array}{l}\text { Neuron } \\
\text { Morphology }\end{array}$ & Compartment & Dimensions (I x w) & $\begin{array}{l}\text { \# of } \\
\text { Segments }\end{array}$ & $\begin{array}{l}\text { Active properties } \\
\text { (max. conductance) }\end{array}$ \\
\hline & Soma & $20 \times 10 \mu \mathrm{m}$ & 21 & $\begin{array}{l}\mathrm{Na}^{+}: 100 \mathrm{pS} / \mu^{2} \\
\mathrm{~K}^{+}: 100 \mathrm{pS} / \mu^{2}\end{array}$ \\
\hline Ball-and-stick & Dendrite & $\begin{array}{l}200-1,000 \mu \mathrm{m}, \\
\text { tapering from } 5 \text { to } 1 \\
\mu \mathrm{m}\end{array}$ & 1 per $\mu \mathrm{m}$ & $\begin{array}{l}\text { Typically passive. } \\
\text { Otherwise, } \mathrm{Na}^{+} \text {and } \mathrm{K}^{+} \\
\text {with linear decrease } \\
\left(100 \text { to } 10 \mathrm{pS} / \mathrm{\mu m}^{2}\right) \text {. }\end{array}$ \\
\hline \multirow{2}{*}{$\begin{array}{l}\text { CA3 and dentate } \\
\text { granule neurons }\end{array}$} & Soma & As reconstructed & 1 per $\mu \mathrm{m}$ & $\begin{array}{l}\mathrm{Na}^{+:}: 100 \mathrm{pS} / \mu^{2} \\
\mathrm{~K}^{+:}: 100 \mathrm{pS} / \mathrm{m}^{2}\end{array}$ \\
\hline & Dendrites & As reconstructed & 1 per $\mu \mathrm{m}$ & Passive. \\
\hline \multirow[b]{2}{*}{$\begin{array}{l}\text { Layer } 5 \\
\text { pyramidal } \\
\text { neuron }\end{array}$} & Soma & As reconstructed & 1 per $\mu \mathrm{m}$ & $\begin{array}{l}\mathrm{Na}^{+}: 100 \mathrm{pS} / \mu^{2} \\
\mathrm{~K}^{+}: 100 \mathrm{pS} / \mu \mathrm{m}^{2}\end{array}$ \\
\hline & Dendrites & As reconstructed & 1 per $\mu \mathrm{m}$ & $\begin{array}{l}\text { Linear decrease of } \mathrm{Na}^{+} \\
\text {and } \mathrm{K}^{+}(100 \text { to } 10 \mathrm{pS} / \\
\left.\mu \mathrm{m}^{2}\right) \text {. Exponential } \\
\text { increase of } \mathrm{HCN} \\
\text { conductance in apical } \\
\text { dendrite. }\end{array}$ \\
\hline \multirow{3}{*}{ All morphologies } & Spines & $\begin{array}{l}\text { Neck: } 1 \times \sim 0.05 \mu \mathrm{m} \\
\text { Head: } 0.5 \times 0.5 \mu \mathrm{m}\end{array}$ & $\begin{array}{l}1 \\
1\end{array}$ & $\begin{array}{l}\text { As in parent dendritic } \\
\text { compartment. }\end{array}$ \\
\hline & $\begin{array}{l}\text { Axon initial } \\
\text { segment }\end{array}$ & $\begin{array}{l}40 \mu \mathrm{m} \text {, tapering from } \\
2 \text { to } 0.5 \mu \mathrm{m}\end{array}$ & 41 & $\begin{array}{l}\mathrm{Na}^{+}: 4000 \mathrm{pS} / \mu^{2} \\
\mathrm{~K}^{+}: 1000 \mathrm{pS} / \mu \mathrm{m}^{2}\end{array}$ \\
\hline & Axon & $2000 \times 0.5 \mu \mathrm{m}$ & 401 & $\begin{array}{l}\mathrm{Na}^{+}: 300 \mathrm{pS} / \mu^{2} \\
\mathrm{~K}^{+}: 60 \mathrm{pS} / \mu \mathrm{m}^{2}\end{array}$ \\
\hline
\end{tabular}

General model parameters: $R_{M}=20 \mathrm{k} \Omega \cdot \mathrm{cm}^{2} ; \mathrm{C}_{\mathrm{M}}=1 \mu \mathrm{F} / \mathrm{cm}^{2} ; \mathrm{R}_{\mathrm{i}}=100 \Omega \cdot \mathrm{cm} ; \mathrm{E}_{\text {pas }}=-55$ to $-85 \mathrm{mV}$, as indicated in text; time steps, $25 \mu \mathrm{s}$; nominal temperature, $37^{\circ} \mathrm{C}$.

hyperpolarization- and cyclic-nucleotide-gated ( $\mathrm{HCN})$ cationic conductance was inserted into dendrites (source code available in ModelDB, entry 124043 ). Spines with neck resistances of $500 \mathrm{M} \Omega$ (Harnett et al., 2012) were positioned at $1 \mu \mathrm{m}$ intervals along dendrites. Axons in all models were $2000 \mu \mathrm{m}$ long, had diameters of $0.5 \mu \mathrm{m}$, and were attached to the soma via a $40 \mu \mathrm{m}$ axon initial segment (AIS) that tapered from $2.0 \mu \mathrm{m}$ (at the soma) to $0.5 \mu \mathrm{m}$ (at the axon). Except for the AIS, voltage-gated conductances were evenly distributed in axons (i.e., axons were unmyelinated; see Table 1 for sodium and potassium channel densities in each neuronal compartment). In the ball-and-stick neuron, somata $(20 \times 10 \mu \mathrm{m})$ were attached to a single tapering $(5 \mu \mathrm{m}$ to $1 \mu \mathrm{m})$ dendrite of variable length $(0.2$ to $1 \mathrm{~mm}$; input resistances ranging from $\sim 170$ to $\sim 450 \mathrm{M} \Omega$ ). In all simulations, models were initiated following a $1 \mathrm{~s}$ passive run to allow active conductances to reach a steady-state. Unless otherwise stated, simulations were generally run with time steps of
$25 \mu s$, and at a nominal temperature of $37^{\circ} \mathrm{C}$.

\section{Simulated synaptic inputs}

In most simulations, synaptic conductances were located on spine heads. AMPA conductances had exponential rise and decay time constants of $0.2 \mathrm{~ms}$ and $2 \mathrm{~ms}$, respectively, a reversal potential of $0 \mathrm{mV}$, and, unless otherwise noted, a maximum conductance of $500 \mathrm{pS}$. NMDA inputs typically had a nominal maximum conductance of $1 \mathrm{nS}$ (typically reaching $\sim 380 \mathrm{pS}$ during individual AMPA+NMDA synaptic events occurring from a membrane potential of -30 $\mathrm{mV}$ ), a reversal potential of $+5 \mathrm{mV}$, and exponential rise and decay time constants of $3 \mathrm{~ms}$ and 90 ms, respectively (Gulledge et al., 2012). Because the NMDA conductance is voltage dependent, in simulations measuring EPSP-spike coupling in the layer 5 pyramidal neuron (Figure 7), and when AMPA conductance was excluded, the maximal synaptic NMDA conductance was increased to $1.2 \mathrm{nS}$ to allow for a level of action potential genesis at depolarized RMPs similar to that observed in simulations using both AMPA and NMDA conductances. Single synaptic events were monitored at the soma and at the dendritic site of synaptic input. For barrages of synaptic events, dendritic voltage responses were measured at the mid-point of the dendritic span receiving synaptic input. During spike threshold tests, action potentials were identified in the midpoint of the axon. During non-spike threshold tests, threshold was determined as somatic events reaching $2 \mathrm{mV}$ (for the CA3 neuron) or $5 \mathrm{mV}$ (for the dentate granule cell) above the somatic RMP, or dendritic events reaching a threshold of $-30 \mathrm{mV}$ locally at the site of synaptic input (all models).

Synaptic barrages of $n$ synaptic activations, delivered to discrete dendritic compartments, were defined by sampling two random variables $n$ times for a set of $n$ pairs. The first random variable in the 
pair determined the site of the $n^{\text {th }}$ synaptic input and was chosen from a uniform distribution spanning integers 0 to 49 (for a $50 \mu \mathrm{m}$ range), which was then applied to the dendritic segment of interest (i.e., from 620-669 $\mu \mathrm{m}$ from the soma). The second random variable, which determined synaptic timing, was chosen from a Gaussian distribution (width of $50 \mathrm{~ms}$ ). Each pattern maintained a single ordered set of sampled pairs. The size of the set varied depending on the number $n$, but the content and order of the pairs did not change for a given pattern. For instance, within one pattern, barrages with $n$ and $n+1$ synaptic activations were identical except for the $n+1^{\text {th }}$ additional activation. These spatiotemporal patterns of synaptic input were moved along dendrites at 10 or $20 \mu \mathrm{m}$ intervals to compare the effect of input location on synaptic responses. Ten different spatiotemporal patterns of synaptic input were generated and applied individually across all dendritic locations to allow statistical determination of the stability of EPSP-spike coupling over input pattern, dendritic location, and RMP. Nominal RMPs were set by uniformly adjusting the reversal potential for the passive leak conductance in all model compartments.

Variation of EPSP-spike coupling and somatic drive was quantified as coefficient of variation (CV; standard deviations normalized by means), which provides a relative measure of mean variability across all dendritic locations and/or membrane potentials independent of response magnitudes (as opposed to measures of absolute range or standard deviation, which are difficult to compare across inputs having different means, and which may overestimate effective variability if functions [e.g., vs distance or voltage] are non-linear; see Figure 1). CVs were typically calculated across all dendritic locations and/or across all RMPs. In long dendrites, inputs to distal dendritic locations became so remote that threshold numbers of synaptic inputs rose exponentially to an infinite value, as at very distal distances even voltageclamping a $50 \mu \mathrm{m}$ dendritic segment to $0 \mathrm{mV}$ would fail to generate action potentials in the axon. Thus, as indicated in our figures, we considered the "relevant" dendritic length to be those dendritic locations proximal to the first local minimum threshold occurring after the first local maximal threshold for simulations having both AMPA and NMDA conductances. This relevant dendritic length was also applied to the analysis of AMPAonly and NMDA-only simulations. In the large CA3 neuron, at very distal locations ( $7.18 \%$ of all trials) thresholds for AMPA-only inputs exceeded 10,000 (our maximum tested threshold), and therefore CVs were calculated for each of the three conductance types (AMPA-only, NMDA-only, and both AMPA and NMDA) using only the trials in which AMPA thresholds were $<10,000$ (i.e., the remaining $92.82 \%$ of trials).

\section{Physiological recordings}

Female and male adult (6- to 10-week-old) C57BL/6J wild-type mice, originally sourced from The Jackson Laboratory (Bar Harbor, ME, USA, stock number 000664; RRID: IMSR_JAX:000664), were bred in facilities accredited by the Association for Assessment and Accreditation of Laboratory Animal Care. Mice were maintained on a $12 \mathrm{~h}-12 \mathrm{~h}$ light-dark cycle with continuous free access to food and water.

To selectively express channelrhodopsin-2 (ChR2) in callosal afferents, we injected $600 \mathrm{~nL}$ of ChR2-carrying AAV virus (AAV9.CAG. hChR2(H134R)-mCherry.WPRE.SV40, diluted 1:10; Addgene \#20938; RRID: Addgene_100054) unilaterally in the medial prefrontal cortex (mPFC) of mice anesthetized with vaporized isoflurane $(2 \%)$. Injection site coordinates were, relative to bregma, $2.10 \mathrm{~mm}$ rostral, $0.48 \mathrm{~mm}$ lateral, and 1.60 $\mathrm{mm}$ ventral to the brain surface. After injection, the microsyringe was held in place for $\sim 5$ min before being slowly withdrawn. Animals recovered for at least 2 weeks before use in electrophysiological experiments. Location of virus injections were confirmed post-hoc in coronal slices of the mPFC. Surgical procedures and postoperative care were optimized so as to eliminate or minimize all forms of animal discomfort, distress, pain, and injury.

Prior to electrophysiological experiments, animals were anesthetized with vaporized isoflurane, decapitated, and brains rapidly removed into aCSF composed of the following (in $\mathrm{mM}$ ): 125 $\mathrm{NaCl}, 25 \mathrm{NaHCO}_{3}, 3 \mathrm{KCl}, 1.25 \mathrm{NaH}_{2} \mathrm{PO}_{4}, 0.5$ $\mathrm{CaCl}_{2}, 6 \mathrm{MgCl}_{2}$ and 25 glucose (saturated with $95 \% \quad \mathrm{O}_{2}-5 \% \mathrm{CO}_{2}$ ). Coronal brain slices $(250 \mu \mathrm{m}$ thick) of the mPFC were cut using a Leica VT 1200 slicer and stored in a holding chamber filled with aCSF containing $2 \mathrm{mM} \mathrm{CaCl}_{2}$ and $1 \mathrm{mM} \mathrm{MgCl}$. Slices were maintained in the holding chamber for 45 minutes at $35^{\circ} \mathrm{C}$, and then at room temperature $\left(\sim 25^{\circ} \mathrm{C}\right)$ until use in experiments.

For experiments, slices were transferred to a recording chamber continuously perfused $(\sim 7 \mathrm{ml} /$ min) with oxygenated aCSF heated to $35-36^{\circ} \mathrm{C}$. To isolate monosynaptic input, aCSF contained $1 \mu \mathrm{M}$ tetrodotoxin (TTX; Cayman Chemical) and $100 \mu \mathrm{M}$ 4-aminopyridine (4-AP; Tocris). L2/3 pyramidal neurons were visually targeted using a $60 \mathrm{X}$ waterimmersion objective. Patch pipettes (5-7 M 2 ) were filled with a solution containing the following (in $\mathrm{mM}$ ): 135 potassium gluconate, $2 \mathrm{NaCl}, 2 \mathrm{MgCl}_{2}$, 10 HEPES, $3 \mathrm{Na}_{2} \mathrm{ATP}$ and $0.3 \mathrm{Na}_{2} \mathrm{GTP}, \mathrm{pH} 7.2$ with 
$\mathrm{KOH}$. Data were acquired using a BVC-700 amplifier (Dagan Corporation) connected to an ITC-18 digitizer (HEKA) driven by AxoGraph software (AxoGraph Scientific; RRID: SCR_014284). Membrane potentials were sampled at $25 \mathrm{kHz}$ and filtered at $5 \mathrm{kHz}$. No correction was made for the liquid junction potential. Synaptic activation was triggered with flashes $(470 \mathrm{~nm} ; 5$ ms) from an LED connected to the microscope epifluorescence port. LED power was adjusted to generate somatic EPSPs of $\sim 10 \mathrm{mV}$ from a resting membrane potential of $-70 \mathrm{mV}$. Fifteen flashevoked EPSPs (15 s inter-trial intervals) were acquired at each of three membrane potentials $(-80,-70$, and $-60 \mathrm{mV})$ set by somatic current injection. D-2-amino-5-phosphonovaleric acid (AP5, $50 \mu \mathrm{M}$; Cayman Chemical), or aCSF (sham), was then bath applied for 5 minutes, and lightevoked EPSPs recorded again at the same three holding potentials.

\section{Statistical analyses}

Results are reported are means \pm standard deviations. Statistical comparison of experimental results from simulations with AMPA-only, NMDAonly, or AMPA-plus-NMDA conductances used oneway repeated-measures ANOVA with post-hoc Šidák-corrected paired Student's t-tests. Comparisons of results within and between groups used either the Student's T-test (two-tailed, paired or unpaired) or one-way ordinary or repeated measures ANOVA with Šidák multiple comparisons post-tests, as appropriate, using Wizard 1.9 (RRID: SCR_016939).

\section{Results}

\section{Effect of synaptic conductance type on individual EPSPS}

We first compared the relative efficacy of individual synapses consisting of AMPA, NMDA, or both AMPA and NMDA conductances in depolarizing the soma of a simplified ball-and-stick model neuron with the resting membrane potential (RMP) set to one of seven values (-85 to $-55 \mathrm{mV}$; see Methods). As expected, the amplitude and kinetics of the resulting EPSPs depended on synaptic conductance type, RMP, and the dendritic location of synaptic input (Figure 1A). Regardless of the type of synaptic conductance, somatic EPSP amplitudes and integrals decremented with synaptic distance from the soma, while amplitudes and integrals at the site of synaptic input, which are shaped by local input impedance and capacitance, became larger at distal dendritic locations (Figure 1B). AMPA-only EPSPs were always larger and faster than NMDA-only responses, and reached maximal amplitudes at the most hyperpolarized membrane potentials, where driving force for the conductance was greatest (dark yellow plots in Figure 1B). On the other hand, due to their voltage-dependence, NMDA-only EPSPs had larger amplitudes and integrals at depolarized membrane potentials (light blue plots in Figure 1B). EPSPs generated by synapses containing both AMPA and NMDA conductances were only slightly larger in amplitude than AMPA-only responses, but had substantially larger integrals due to slower decay kinetics, especially at depolarized RMPs (light green plots in Figure 1B). Regardless of dendrite length, when the variability of somatic EPSP amplitudes and integrals (quantified as coefficient of variation, CV) was calculated for EPSPs across all dendritic locations at each RMP (Figure 1C), or across all RMPs for each dendritic location (Figure 1D), CVs of AMPA+NMDA inputs were always lower than those for corresponding AMPA-only EPSPs. This effect was amplified when "total CVs" were calculated across all dendritic input locations and RMPs (Figure 1E), leading to CVs that were always lowest when both AMPA and NMDA conductances were present at the synapse. In the above analyses, and in all additional figures, we use CV as a measure of variability across dendritic location and/or RMP, as it provides a relative measure independent of individual response magnitude (see Methods). As a comparison, we plotted ranges and standard deviations, across all dendritic locations and RMPs, for somatic EPSP amplitudes and integrals (Figure 1F). Even in the face of larger absolute amplitudes and integrals, AMPA+NMDA synapses generated smaller ranges and standard deviations for amplitudes and integrals than did AMPA-only inputs. However, because range and standard deviation are absolute (e.g., not normalized to response magnitude), these metrics can be difficult to interpret. For instance, the range of somatic EPSP amplitudes and integrals shown in Figure 1F initially drops with increasing dendritic length, despite the increased electrotonic diversity of longer dendrites, because the amplitudes of somatic EPSPs become much smaller in larger neurons having lower input resistances (e.g., mean individual somatic AMPA+NMDA EPSP amplitudes at $-85 \mathrm{mV}$ drop over 3 -fold, from $2.29 \pm 0.01 \mathrm{mV}$ for inputs to a $200 \mu \mathrm{m}$ dendrite, to $0.64 \pm 0.08 \mathrm{mV}$ for inputs in a $1000 \mu \mathrm{m}$ dendrite). Thus, in subsequent analyses and figures we use CV as a measure of relative variability of EPSPs generated across dendrite locations and/or RMPs. 
bioRxiv preprint doi: https://doi.org/10.1101/566117; this version posted August 11,2019 . The copyright holder for this preprint (which was not certified by peer review) is the author/funder, who has granted bioRxiv a license to display the preprint in perpetuity. It is made available under

A aCC-BY-NC 4.0 International license.

Li et al., page 6

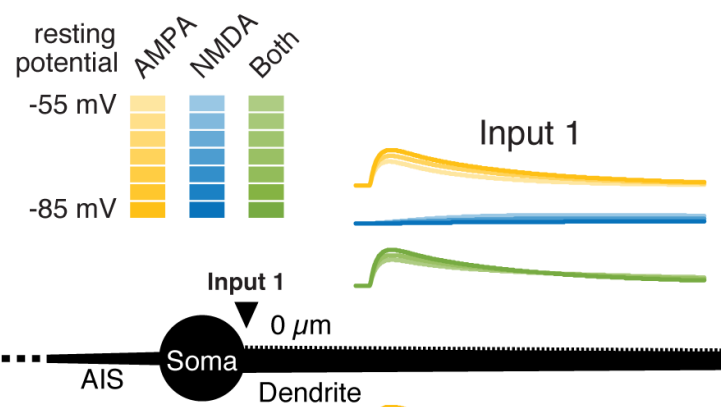

Recorded locally in the dendrite

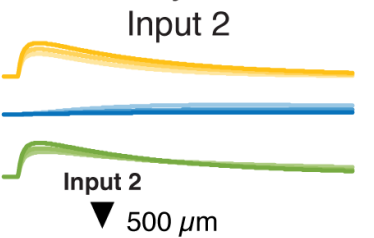

Input 3
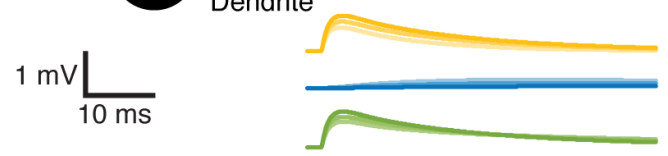

B

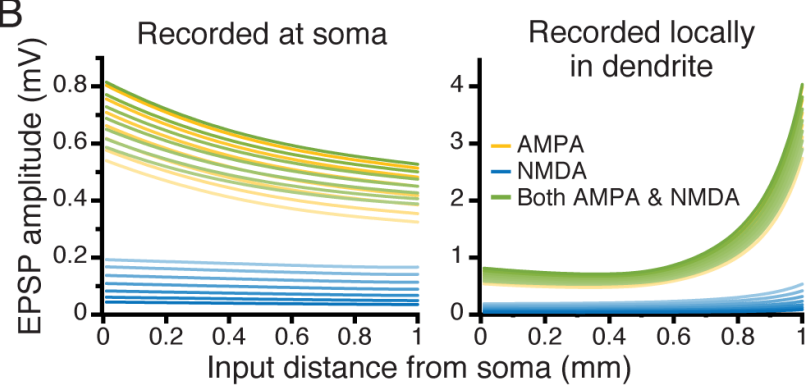

Recorded at soma
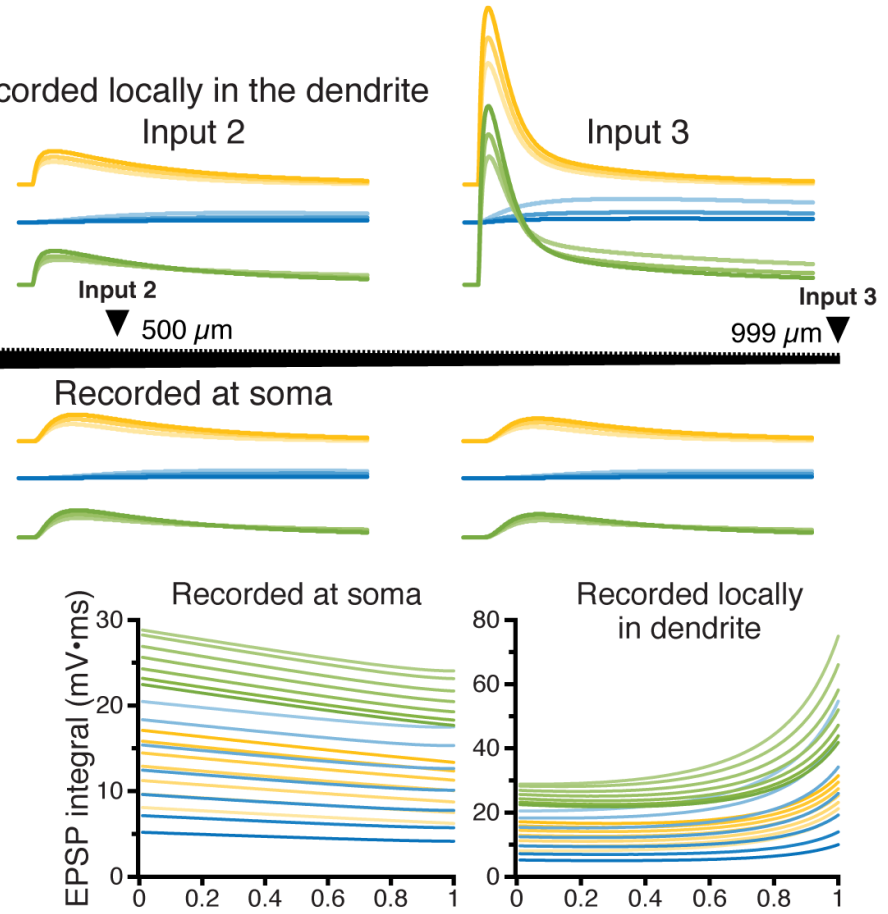

Recorded locally

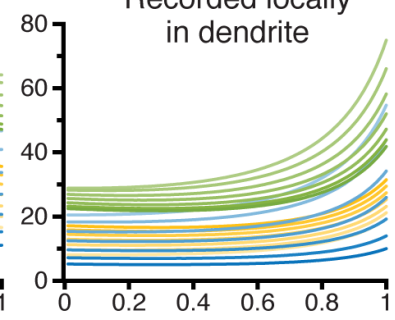

Input distance from soma $(\mathrm{mm})$

C CVs calculated for somatic EPSPs across all dendritic locations, for each RMP
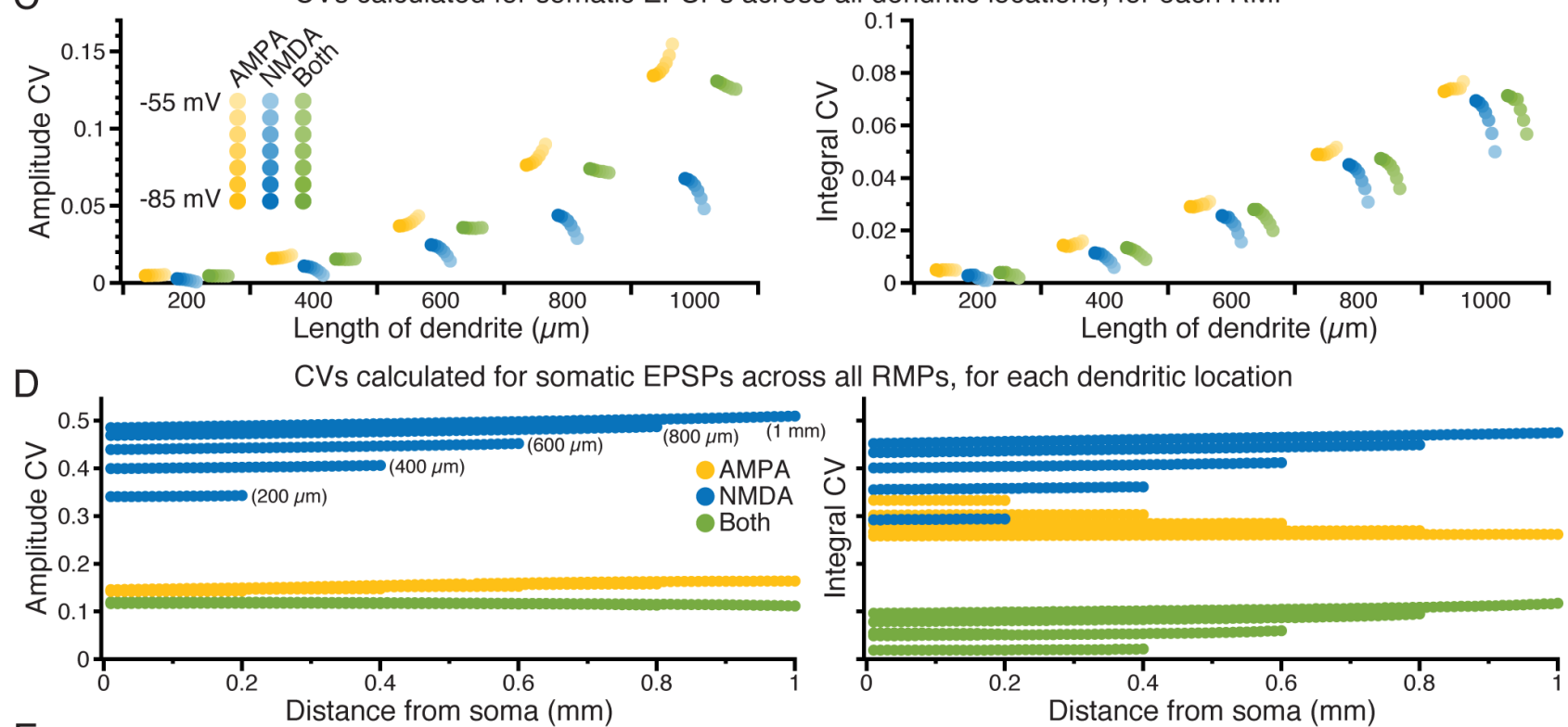

E

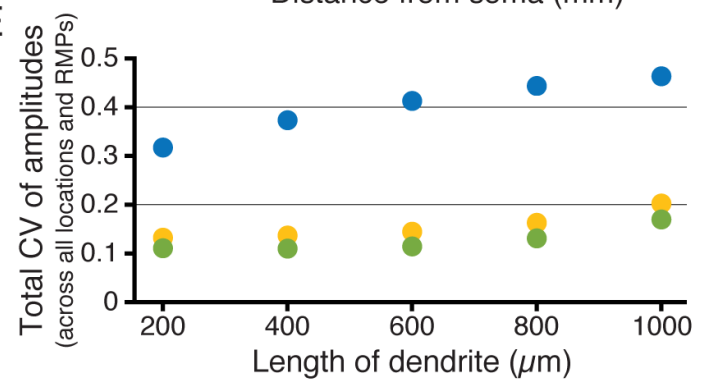

F

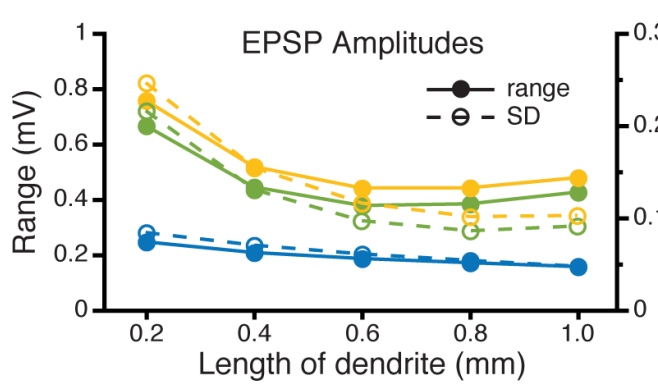

AMPA NMDA Both
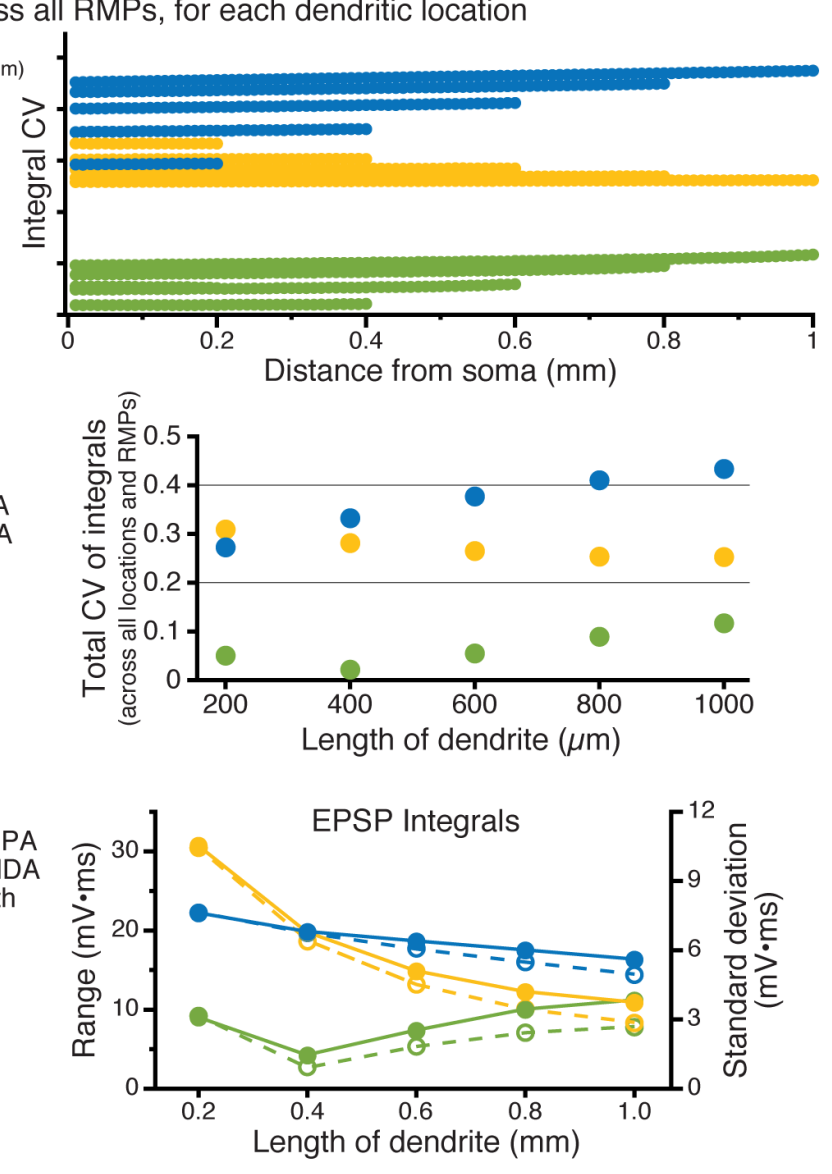
Impact of synaptic conductance on synaptic integration

Since the presence of the NMDA conductance at individual synapses reduced distance- and RMPdependent variability of somatic EPSPs relative to AMPA-only inputs, we reasoned that they may also act to increase the fidelity of synaptic integration in response to barrages of synaptic input occurring at different dendritic locations and/or at different RMPs. To test this, we measured EPSP-spike coupling in the ball-and-stick model neuron and compared, across dendritic location and RMP, the threshold number of synaptic activations necessary for action potential initiation in the axon (Figure 2A). Ten stochastic spatiotemporal patterns of synaptic input ("synaptic barrages," see Methods) were delivered to progressively more distal $50 \mu \mathrm{m}$ spans of the dendrite. For simulations involving AMPA-only, NMDA-only, or both synaptic conductances, the number of activated synapses within each barrage was iteratively increased until an action potential was initiated. For each pattern of synaptic input, the threshold number of synapses necessary for action potential generation was determined for inputs occurring at different dendritic locations (10 or $20 \mu \mathrm{m}$ intervals) and across seven RMPs (-85 to $-55 \mathrm{mV}$ ). As with single EPSPs, identical barrages of synaptic input generated ever-larger local dendritic depolarization at progressively more distal dendritic locations. While this increase in amplitude with distance was linear when inputs involved AMPA conductances only, incorporation of the NMDA conductance, by itself or in combination with the AMPA conductance, allowed for supralinear distancedependent increases in response amplitude and width, including long-lasting regenerative NMDA spikes, at distal dendritic locations (Figure 2B).

For AMPA-only synapses, the mean threshold number of synaptic inputs increased with distance from the soma, or with hyperpolarization of the RMP (Figure 2C, left). This result reflects the distance-dependent voltage attenuation of summated EPSPs, as well as the reduced total synaptic current due to the diminished driving force occurring in narrow, high-impedance dendrites (where local EPSPs are intrinsically larger). On the other hand, when synapses contained only the NMDA conductance, the threshold number of synapses decreased with depolarization of the RMP, but was fairly uniform across distance in the proximal dendrite before becoming lower at distal locations (Figure 2C, middle). This shape resulted from distance-dependent voltage attenuation of somatic EPSPs combined with the generation of progressively larger synaptic currents at more distal, high-impedance dendritic locations, where NMDA spikes of increasing duration were observed (see Figure 2B). At very distal locations, and especially at depolarized RMPs where voltagedependent NMDA conductances were near maximal, thresholds increased sharply with additional distance in ways similar to those observed for AMPA-only inputs. This reflects strong distance-dependent voltage attenuation at distal locations, combined with limited ability to further increase synaptic current due to the greatly reduced synaptic driving force during full-blown NMDA spikes that approach the NMDA reversal potential. Remarkably, when synapses contained both AMPA and NMDA conductances, synaptic thresholds for action potential generation were overall lower, less sensitive to changes in RMP, and less variable across distance than were thresholds for AMPA-only or NMDA-only synaptic inputs (Figure 2C, right). Across both dendritic location and RMP, and consistently over ten stochastic input patterns, the CV of action potential thresholds was reduced when synapses contained both AMPA and NMDA conductances, and this effect was amplified in longer dendrites (Figure 2D, right), likely reflecting the greater electrotonic diversity across input locations. When total CVs were calculated across all dendritic locations and RMPs, they were consistently lowest when synapses contained both conductances (Figure 2D). The stabilizing effect of the NMDA conductance on synaptic thresholds across dendritic location and RMP persisted when inputs occurred on non-spiny dendritic shafts (Figure 2D, middle), and was mimicked and amplified by the

\section{Figure 1. (facing page) Impact of synaptic conductance on the variability of individual EPSPs.}

$\boldsymbol{A}$, Synapses were activated individually along the dendrite $(1 \mathrm{~mm})$ of a simple ball-and-stick model neuron (black; not to scale). Shown are local dendritic (top) and somatic (bottom) EPSPs generated at the three indicated dendritic locations across three different resting membrane potentials (RMPs; as indicated by color depth). $\boldsymbol{B}$, Plots of the amplitudes (left) and integrals (right) of EPSPs measured at the soma, or locally at the site of synaptic input, according to synaptic location. Synaptic conductances and RMPs are color-coded as in $\boldsymbol{A}$. $\boldsymbol{C}$, Plots of coefficients of variation (CVs) for somatic EPSP amplitudes (left) and integrals (right), calculated across all dendritic locations for each color-coded synaptic conductance and RMP, for model neurons with the indicated dendritic lengths. $D$, Similar to $\boldsymbol{C}$, but for $\mathrm{CVs}$ calculated across all RMPs for each synaptic location in dendrites of the indicated lengths. $E$, Plots of the "total CV" for EPSP amplitudes (left) and integrals (right) calculated across all dendritic locations and RMPs in model neurons having the indicated dendritic lengths. $\boldsymbol{F}$, Alternative measures of the variability (absolute range and standard deviation) of somatic EPSP amplitudes (left) and integrals (right), calculated across all RMPs and synaptic locations for inputs having the indicated color-coded synaptic conductances. 

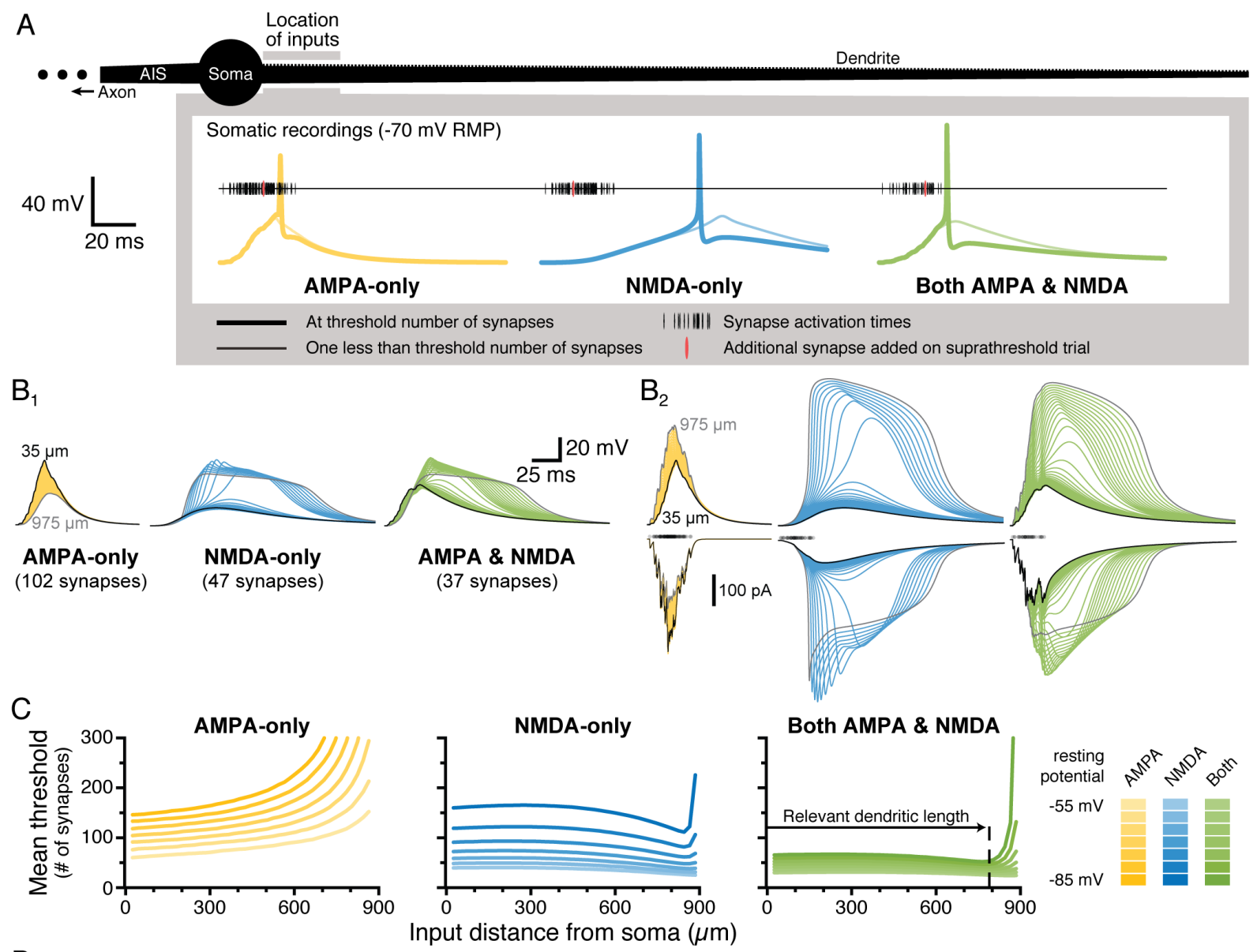

D

Spiny, passive dendrite

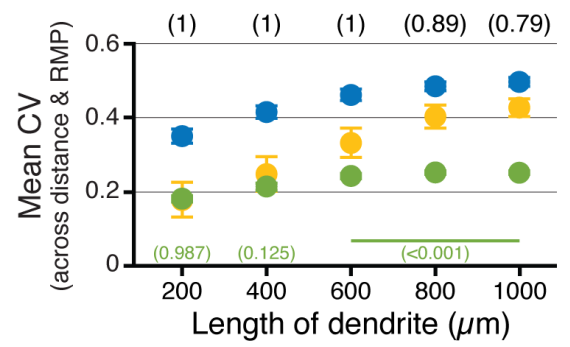

No spines, passive dendrite

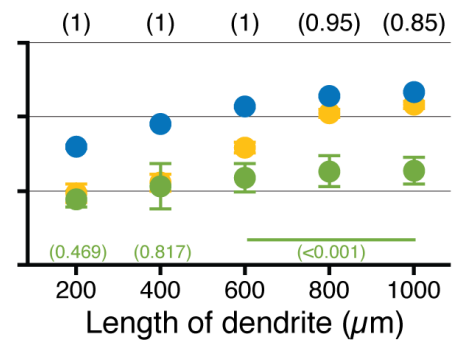

Spiny, active dendrite

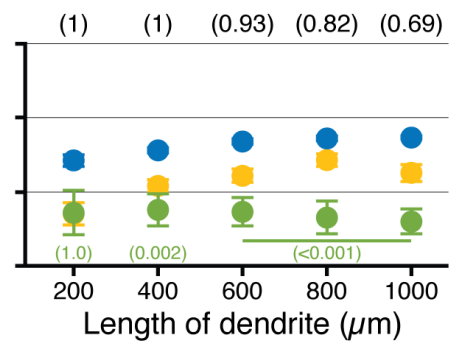

Figure 2. The combination of synaptic AMPA and NMDA conductances stabilizes EPSP-spike coupling.

$A$, A spiny ball-and-stick neuron (black) receiving progressively longer iterative trains of a static-random spatiotemporal pattern of synaptic input. Just-threshold (thick traces) and just-subthreshold (thin traces) voltage responses in the soma for AMPA-only (yellow), NMDA-only (blue), or both AMPA and NMDA (green) synaptic conductances in response to inputs arriving within the first $50 \mu \mathrm{m}$ of the dendrite. $\mathbf{B}$, Somatic $\left(\mathbf{B}_{1}\right)$ and dendritic $\left(\mathbf{B}_{2}\right.$, top) voltage responses for identical subthreshold synaptic barrages at each dendritic location (superimposed) for the indicated synaptic conductance types (RMP is $-70 \mathrm{mV}$ ). Summed total synaptic currents are shown $\mathbf{B}_{2}$, bottom. Note the progressive development of NMDA spikes at ever-more-distal locations (centered from $35 \mu \mathrm{m}$ [black traces] to $950 \mu \mathrm{m}$ [gray traces] from the soma) when the NMDA conductance is available. Timings of synaptic activations are shown with semi-transparent black dots above the synaptic currents in $\mathbf{B}_{2}$. $\boldsymbol{C}$, Plots of the mean threshold numbers of synaptic activations necessary to initiate action potentials at different locations in the dendrite for synaptic inputs having AMPA-only (left; yellow), NMDA-only (middle; blue), or AMPA and NMDA (right; green) conductances, across seven different resting membrane potentials ( -55 to $-85 \mathrm{mV}$, as indicated by color depth). $\boldsymbol{D}$, Plots of mean CVs ( \pm standard deviations) calculated for the threshold number of synapses for each pattern of input $(n=10)$, across all locations along the relevant dendritic length (in parentheses at top; see Methods) and resting membrane potentials (RMPs), for inputs having AMPA-only (yellow), NMDA-only (blue), or both AMPA and NMDA (green) conductances in dendrites of the indicated lengths. Data in the left panel are from our standard ball-and-stick neurons having inputs onto dendritic spines along a passive dendrite. The middle panel shows mean total CVs for inputs onto non-spiny passive dendrites of the indicated lengths, while the right panel shows total CVs for inputs onto spiny active dendrites. In all cases, CVs were lowest when both AMPA and NMDA conductances were present. For any dendritic length, across all synaptic conductances, CVs for the three synaptic conductance types significantly differed ( $p<$ 0.001 ; ANOVAs), with the combination of both conductances being significantly reduced for dendrites longer than 400 $\mu \mathrm{m}$. P-values for post-hoc (Šidák-corrected) comparisons between AMPA-only and AMPA plus NMDA conductances are shown in green. 


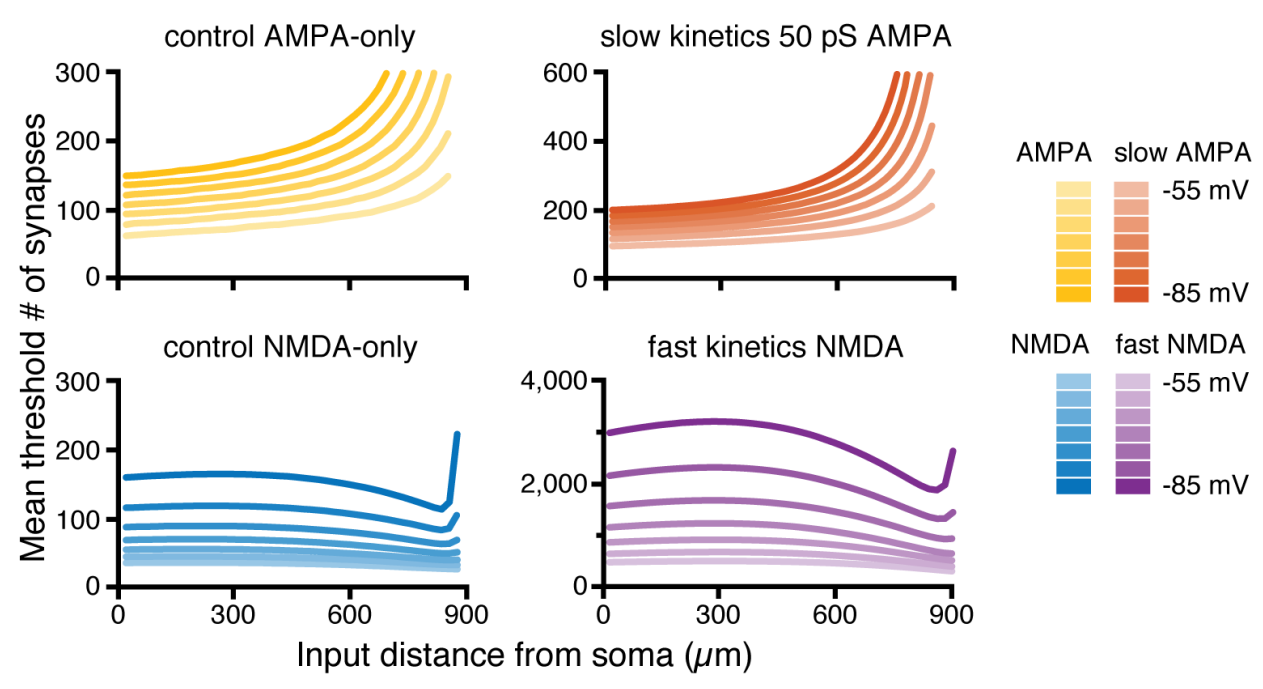

Figure 3. The voltage-dependence of NMDA conductances stabilizes synaptic integration.

Shown are plots of threshold number of synapses for action potential generation in a 1-mm-long ball-and-stick model neuron receiving barrages of synaptic input at $20 \mu \mathrm{m}$ intervals along the dendrite (as in Figure 2). Plots on the left are thresholds for AMPA-only (top, yellow), and NMDA-only (bottom, blue) synaptic conductances, reproduced from Figure $2 \mathrm{~B}$, for barrages occurring at seven resting membrane potentials ( -85 to $-55 \mathrm{mV}$, as indicated by color-depth). On the right are results from simulations in which the voltage-independent AMPA conductance (reduced to $50 \mathrm{pS}$ ) was given slow, NMDA-like kinetics ( $3 \mathrm{~ms}$ rise, $90 \mathrm{~ms}$ decay; top, red), or in which the voltage-dependent NMDA conductance was given fast, AMPA-like kinetics ( $0.2 \mathrm{~ms}$ rise, 2 ms decay; bottom, purple). Note the difference in scale bars in right panels. Voltage-dependent synaptic conductances generated threshold vs distance curves that were flat or decreased with distance from the soma.

addition of voltage-gated sodium and potassium conductances (see Table 1) to dendrites (Figure 2D, right). Adding these active conductances to dendrites reduced the $\mathrm{CV}$ of thresholds for all synaptic conductance types (compare the right and left panels of Figure 2D; $p<0.01$ for each conductance type and dendritic length; Šidákcorrected paired Student's t-tests), except for AMPA-only inputs in the $400 \mu \mathrm{m}$ dendrite $(p=$ 0.118). Together, these data demonstrate that, across a range of dendritic lengths, combining synaptic AMPA and NMDA conductances reduces the variability of EPSP-spike coupling relative to inputs having AMPA or NMDA conductance alone.

Voltage-dependence of the NMDA conductance stabilizes EPSP-spike coupling

The NMDA conductance differs from the AMPA conductance in two key ways: it is voltage dependent and has slower kinetics. To test the relative impact of these properties on EPSP-spike coupling, we simulated two modified NMDA conductances: one lacking voltage-dependence, and one retaining voltage-dependence, but having AMPA-like kinetics. We then determined the threshold number of synaptic activations, across dendritic locations and RMPs, to initiate action potentials in the ball-and-stick neuron (Figure 3). Removing the voltagedependence of the NMDA conductance (while also reducing its maximum conductance to $50 \mathrm{pS}$ ) led to threshold curves that qualitatively mirrored those of AMPA-only conductances, in that thresholds increased with distance from the soma and/or with hyper-polarization of the RMP (Figure 3). On the other hand, endowing the voltagedependent NMDA conductance with AMPA-like kinetics led to higher absolute thresholds that mimicked the normal NMDA conductance in maintaining fairly uniform synaptic thresholds across most dendritic locations (Figure 3). These findings demonstrate that the voltage-dependence of the NMDA conductance, rather than its slower kinetics, allows for stabilization of EPSP-spike coupling.

\section{Synaptic integration in morphologically realistic neurons}

The simulations above reveal that, in simplified neuron morphologies, the presence of both AMPA and NMDA conductances at synapses reduce location- and RMP-dependent variability of somatic responses to spatially restricted barrages of synaptic input. To determine the impact of synaptic conductance type on synaptic integration in realistic neuronal morphologies, we placed spinous synapses at $1 \mu \mathrm{m}$ intervals across the dendritic trees of two reconstructed neurons: a relatively large CA3 pyramidal neuron (Figure 4A), and a smaller dentate granule neuron (Figure 4D). Because of the large size of these neurons, it was not possible to drive action potential generation with barrages of spatially restricted $(50 \mu \mathrm{m})$ synaptic input, as clamping distal $50 \mu \mathrm{m}$ dendritic spans to $0 \mathrm{mV}$ failed to depolarize the axon initial segment to action potential threshold. Instead, we set arbitrary thresholds of somatic depolarization and iteratively activated expanding stochastic patterns of synaptic input at different dendritic locations. In the CA3 neuron (Figure 4B), somatic threshold was set to $2 \mathrm{mV}$ above RMP (RMP set to $-80,-70$, or $-60 \mathrm{mV}$ ) and synaptic barrages were 
A

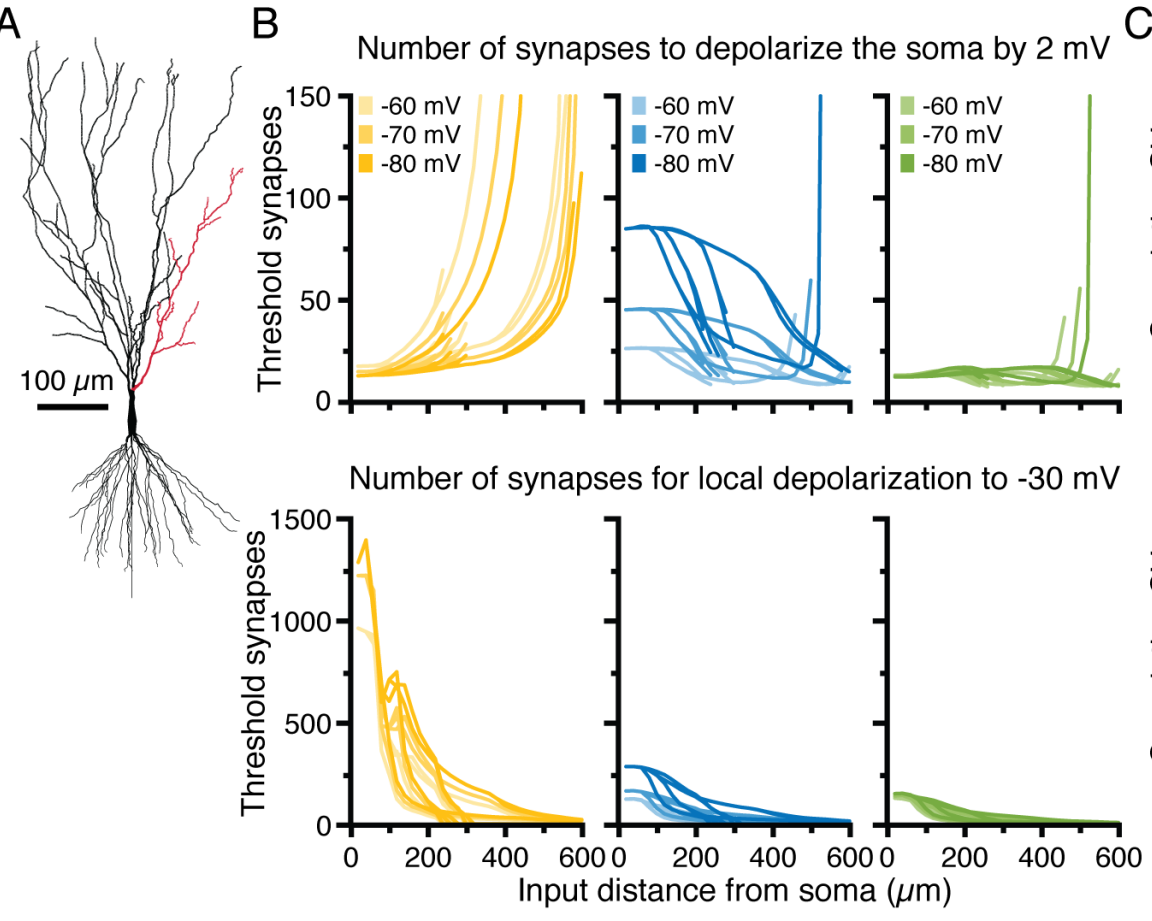

C
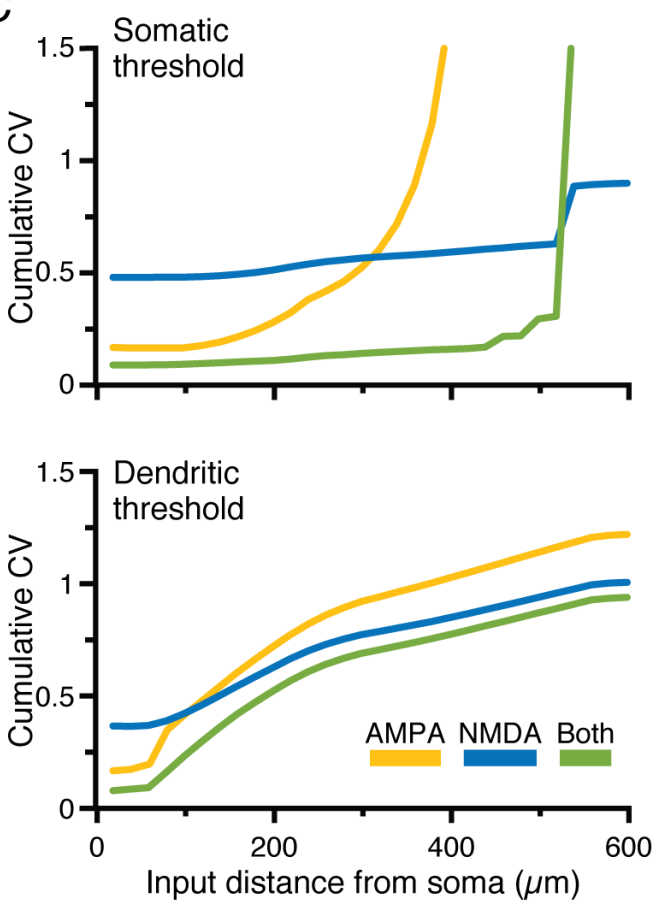

D

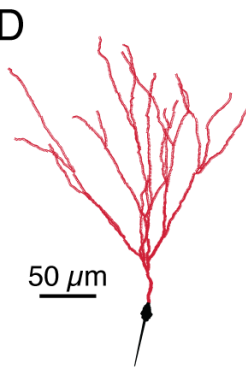

$E$

Number of synapses to depolarize the soma by $5 \mathrm{mV}$
$\mathrm{F}$
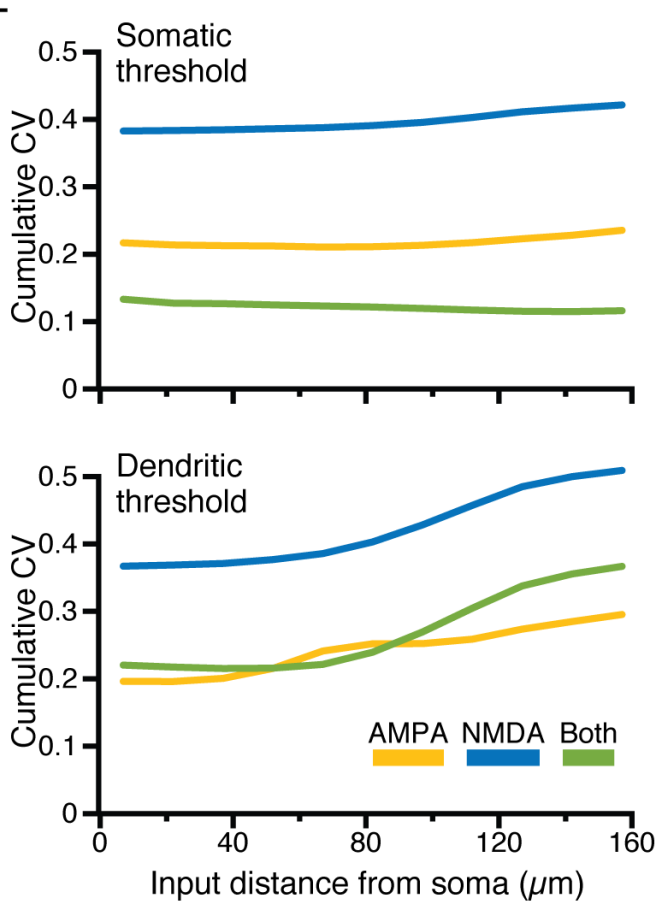

Figure 4. Impact of synaptic conductance in realistic neuron morphologies.

$\boldsymbol{A}$, Reconstructed dendritic tree of a CA3 pyramidal neuron. $\boldsymbol{B}$, Plots of the minimum number of synaptic activations necessary to drive a $2 \mathrm{mV}$ depolarization at the soma (top), or $30 \mathrm{mV}$ depolarization of the local dendritic shaft (bottom), in progressively more distal $50 \mu \mathrm{m}$ segments of the red dendrite in $\mathrm{A}$, experiencing an expanding static-random spatiotemporal pattern of synaptic input. Colors (yellow, blue, and green) indicate AMPA, NMDA, and both AMPA and NMDA synaptic conductances, respectively. C, Plots of cumulative CV for the threshold number of synapses necessary to drive $2 \mathrm{mV}$ somatic depolarization (top) or dendritic depolarization to $-30 \mathrm{mV}$ (bottom) across all dendritic locations and membrane potentials $(-60$ to $-80 \mathrm{mV})$. Y-axes are truncated at a value of 1.5 to show main effect of synaptic conductance on cumulative CV. $\boldsymbol{D}$, Reconstructed dendritic tree of a dentate granule neuron. $\boldsymbol{E}$, Plots of the minimum number of synaptic activations necessary to drive a $5 \mathrm{mV}$ depolarization at the soma (top), or $30 \mathrm{mV}$ depolarization of the local dendritic shaft (bottom), in progressively more distal $50 \mu \mathrm{m}$ segments of the red dendritic arbor in $\boldsymbol{D}$, each experiencing an expanding static-random spatiotemporal pattern of synaptic input. Colors indicate AMPA, NMDA, and both AMPA and NMDA synaptic conductances, as in $\boldsymbol{B}$. $\boldsymbol{F}$, Plots of cumulative CV for the threshold number of synapses necessary to drive $5 \mathrm{mV}$ somatic depolarization (top) or dendritic depolarization to $-30 \mathrm{mV}$ (bottom) across all dendritic locations and membrane potentials in the dentate granule neuron. 
delivered to $50 \mu \mathrm{m}$ spans along the apical dendritic branches indicated in red in Figure 4A (at $20 \mu \mathrm{m}$ increments). When synapses contained only the AMPA conductance, the threshold number of synapses to generate a $2 \mathrm{mV}$ somatic depolarization increased with distance from the soma, or with depolarization of the RMP, as voltage attenuation and reduced driving force impaired synaptic depolarization of the soma (Figure 4B, yellow plots in top panels). In contrast, when synapses contained only the NMDA conductance, the threshold number of synapses to depolarize the soma by $2 \mathrm{mV}$ decreased with distance from the soma and/or with depolarization of the RMP, as distance-dependent increases in local input impedance, and/or depolarization of the RMP, enhanced the voltage-dependent NMDA conductance (Figure 4B, blue plots in top panels). However, combining both AMPA and NMDA conductances generated threshold numbers of synapses that were lower and relatively uniform across dendritic location and RMP (Figure 4B, green plots in top panels), as reflected in lower cumulative $\mathrm{CVs}$ for thresholds calculated across all RMPs for increasingly distant dendritic locations (green plot in Figure 4C, top). At very distal locations, where thresholds rose steeply for all synaptic conductances, the CV of AMPA-plusNMDA inputs was disproportionally affected due to the much smaller thresholds in the more proximal dendritic tree, leading to overall mean cumulative $\mathrm{CV}$ s that were lowest for NMDA-only conductances $(0.97 \pm 0.05)$ and higher for AMPA-only (4.06 \pm $0.12)$ and combined $(1.73 \pm 0.19)$ conductances (n $=10$ stochastic patterns of synaptic input; $p<$ 0.001 , repeated-measures ANOVA and Šidákcorrected post-tests). Overall, mean CVs for synaptic thresholds, calculated across all RMPs and dendritic locations, were $2.64 \pm 0.48,0.68$ \pm 0.01 , and $0.20 \pm 0.01$, respectively, for AMPAonly, NMDA-only, and AMPA-plus-NMDA conductances $(p<0.001)$. These results further demonstrate that the combined synaptic presence of AMPA and NMDA conductances reduces distance- and RMP-dependent variability of synaptic integration, as measured at the soma.

When we instead determined the threshold number of synapses necessary to depolarize the local dendritic compartment to $-30 \mathrm{mV}$ (arbitrarily chosen as approximating calcium-spike threshold; Golding \& Spruston, 1998), threshold numbers of synapses decreased with distance from the soma and with depolarization of the RMP for all synapse types (Figure 4B, bottom), and combining AMPA and NMDA conductances had a more modest impact on lowering CVs for thresholds across dendritic location and RMPs (Figure 4C, bottom).
For all dendritic locations and RMPs, mean CVs per input pattern were $1.35 \pm 0.03,1.07 \pm 0.01$, and $1.00 \pm 0.02$, for AMPA-only, NMDA-only, and both conductances, respectively $(p<0.001$, repeatedmeasures ANOVA and Šidák-corrected post-tests).

Similar results were observed in the smaller dentate granule neuron (Figure 4D), where threshold numbers of synapses for $5 \mathrm{mV}$ somatic depolarizations were determined for $50 \mu \mathrm{m}$ dendritic segments (at $20 \mu \mathrm{m}$ increments) across the entire dendritic tree. As observed in the CA3 neuron, the threshold number of AMPA-mediated synaptic inputs increased with distance from the soma, or with depolarization of the RMP (Figure 4E, yellow plots in top panel), due to distancedependent voltage attenuation and reduced synaptic driving force, respectively. Conversely, for NMDA-mediated inputs, synaptic thresholds decreased with distance from the soma, or with depolarization of the RMP (Figure 4E, blue plots in top panels). The combined presence of synaptic AMPA and NMDA conductances minimized the impact of dendritic location and/or RMP on threshold numbers of synaptic inputs (Figure 4E, green plots in top panels), and greatly reduced the cumulative CVs of thresholds calculated across RMPs for increasingly distant dendritic locations (Figure 4F, top). Mean CVs for spatiotemporal input patterns, calculated across all dendritic locations and RMPs, were $0.21 \pm 0.03,0.43 \pm 0.01$, and $0.07 \pm 0.02$, for AMPA-only, NMDA-only, and AMPA and NMDA conductances, respectively $(p<$ 0.001 , repeated-measures ANOVA and Śidákcorrected post-tests). However, as was true in the CA3 pyramidal neuron, when measuring thresholds for local dendritic depolarization to $-30 \mathrm{mV}$, there was less impact of combining synaptic conductances (Figure 4E,F, bottom panels). For dendritic thresholds, mean CV across dendritic location and RMP was lowest for AMPA-only inputs $(0.31 \pm 0.02)$, relative to NMDA-only $(0.54 \pm 0.02)$ or both conductances $(0.39 \pm 0.01 ; \mathrm{n}=10$ stochastic patterns of synaptic input; $p<0.001$, repeated-measures ANOVA with Šidák-corrected post-tests), confirming that the stabilizing effect of combining AMPA and NMDA conductances is most robust when considering orthodromic signal transmission from small, high-impedance dendritic compartments toward the larger soma and its associated axon.

\section{Integration of distributed synaptic input}

We next tested the impact of conductance type on the integration of distributed synaptic input (Figure 5). In simulations in ball-and-stick model neurons, we randomly distributed along dendrites sets of five excitatory inputs containing AMPA, 
NMDA, or both synaptic conductances (Figure 5A). Somatic EPSPs were recorded in response to simultaneous coactivation of all five synaptic inputs

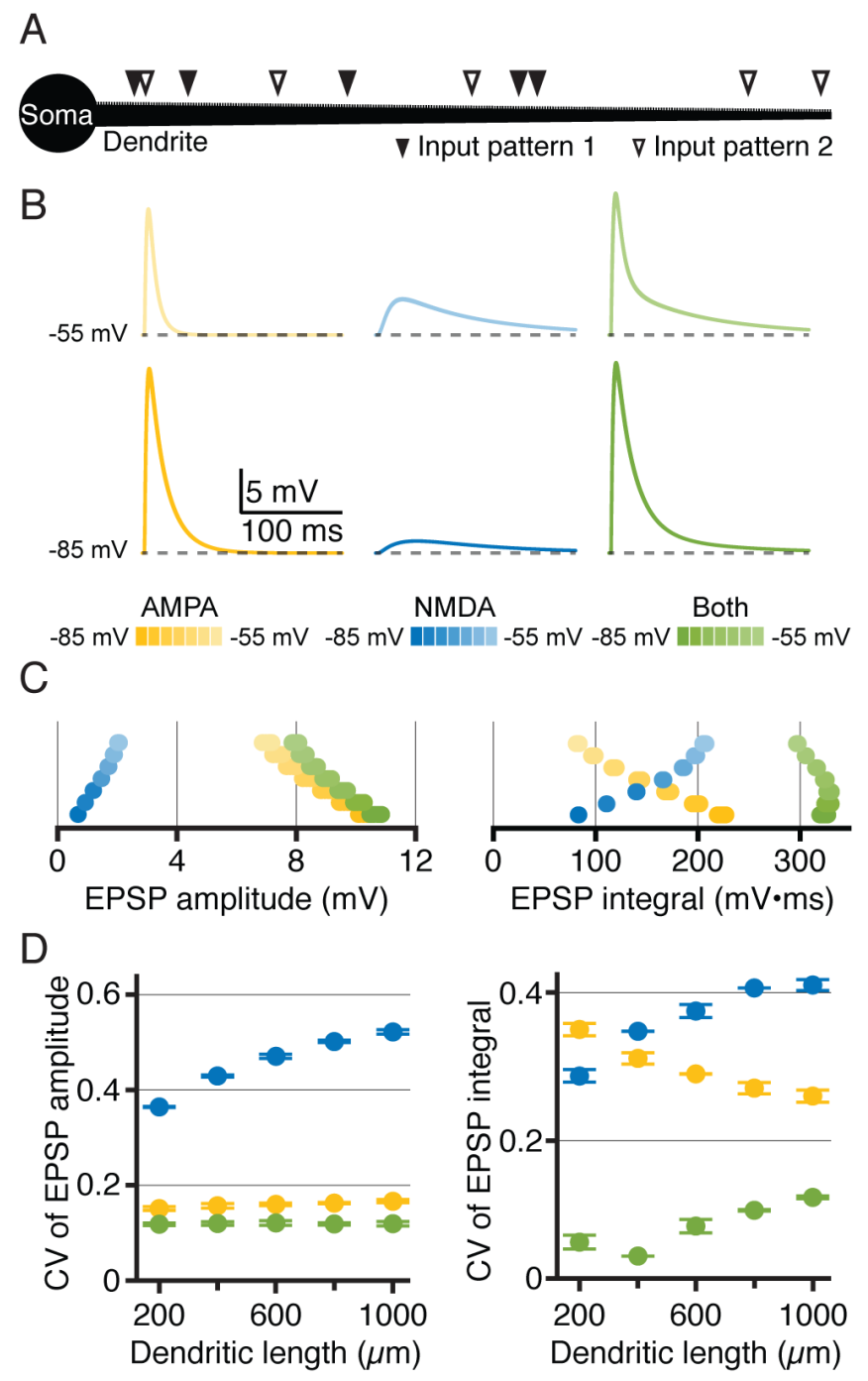

Figure 5. Combining AMPA and NMDA conductances stabilizes synaptic integration of coincident input distributed across the dendritic tree.

$\boldsymbol{A}$, Ball-and-stick model neuron (black; 200 um dendrite, not to scale) with spinous synaptic inputs at $1 \mu \mathrm{m}$ intervals. Shown with open and closed arrowheads are two sets of five coincident inputs placed randomly along the dendrite. $\boldsymbol{B}$, Twenty superimposed EPSPs resulting from different spatial patterns of coincident synaptic input at four different membrane potentials and with AMPA (yellow), NMDA (blue), or AMPA and NMDA (green) conductances in the ball-and-stick model. C, Plots of somatic EPSP amplitudes (left) and integrals (right) for simulated synaptic input in the ball-and-stick neuron $(n=20$ patterns per initial RMP). RMPs are indicated by color, as in $\boldsymbol{B}$. $\boldsymbol{D}$. Plots of mean CV ( \pm standard deviation) for EPSP amplitudes (left) and integrals (right) for simulated synaptic inputs across all RMPs in ball-andstick neurons with various length dendrites.
( $n=20$ sets of inputs), repeated across seven RMPs (-85 to $-55 \mathrm{mV}$; Figure 5B). As expected, NMDA-only synapses generated the smallest EPSP amplitudes (mean response across all RMPs was $1.4 \pm 0.5 \mathrm{mV}$ in the $200 \mu \mathrm{m}$ dendrite), with AMPA-only and AMPA-plus-NMDA synapses generating comparably larger EPSPs, at $8.6 \pm 1.1$ and $9.2 \pm 0.9 \mathrm{mV}$, respectively, in the $200 \mu \mathrm{m}$ dendrite (Figure 5C, left). Similar effects of synaptic conductance on EPSP amplitude were observed in dendrites of all tested lengths. On the other hand, mean EPSP integrals were similar for NMDA-only and AMPA-only inputs (149 \pm 49 and $155 \pm 43 \mathrm{mV} \cdot \mathrm{ms}$, respectively, in the $200 \mu \mathrm{m}$ dendrite), but consistently larger (at $318 \pm 12$ $\mathrm{mV} \cdot \mathrm{ms}$ ) when both AMPA and NMDA conductances were present (Figure 5C, right), with similar relationships between synaptic conductance and EPSP integrals existing for all dendritic lengths. However, as can be seen in Figures 5B and $\mathbf{C}$, the range of somatic EPSP amplitudes and integrals across RMPs depended on the type(s) of glutamate conductance at synapses, and the CVs of EPSP amplitudes and integrals, as measured across RMPs for each pattern of synaptic input, were always lowest when both AMPA and NMDA conductances were present $(p<0.001$ for each case; repeated-measures ANOVA with Šidákcorrected post-tests; see Figure 5D).

To test whether NMDA conductances might similarly reduce the variability of EPSP amplitudes and/or integrals in real neurons, we optogenetically activated monosynaptic corticocortical afferents in slices of mouse prefrontal cortex bathed in $1 \mu \mathrm{M}$ TTX and $100 \mu \mathrm{M}$ 4-AP, and recorded EPSPs in layer $2 / 3$ pyramidal neurons before and after bath application of the NMDA receptor blocker AP5 (50 $\mu \mathrm{M}$; Figure 6). In baseline conditions, when both AMPA and NMDA receptors were available, mean EPSP amplitudes were $11.4 \pm 5.7 \mathrm{mV}$ at $-80 \mathrm{mV}(\mathrm{n}$ $=14)$. Depolarizing the membrane potential generated modest reductions in EPSP amplitude, to $11.1 \pm 4.9 \mathrm{mV}$ at $-70 \mathrm{mV}$, and $9.5 \pm 4.0 \mathrm{mV}$ at -60 $\mathrm{mV}(\mathrm{p}=0.006$, repeated measures ANOVA). In contrast, EPSP integrals increased with membrane depolarization, being $650 \pm 525 \mathrm{mV} \cdot \mathrm{ms}$ at $-80 \mathrm{mV}$, $813 \pm 704 \mathrm{mV} \cdot \mathrm{ms}$ at $-70 \mathrm{mV}$, and $831 \pm 588$ $\mathrm{mV} \cdot \mathrm{ms}$ at $-60 \mathrm{mV}(\mathrm{p}=0.018)$. Bath application of AP5 reduced mean EPSP amplitudes and integrals across the board (Figure 6C), but enhanced the impact of membrane potential on EPSP amplitudes. In AP5, EPSP amplitudes were 10.1 $\pm 5.5 \mathrm{mV}$ at $-80 \mathrm{mV}, 8.4 \pm 4.4 \mathrm{mV}$ at $-70 \mathrm{mV}$, and $7.4 \pm 3.7 \mathrm{mV}$ at $-60 \mathrm{mV}(\mathrm{p}<0.001$; repeated measures ANOVA), while integrals were $496 \pm 436$ $\mathrm{mV} \cdot \mathrm{ms}, 516 \pm 511 \mathrm{mV} \cdot \mathrm{ms}$, and $533 \pm 500 \mathrm{mV} \cdot \mathrm{ms}$, respectively, at $-80,-70$, and $-60 \mathrm{mV}(p=0.676)$. 

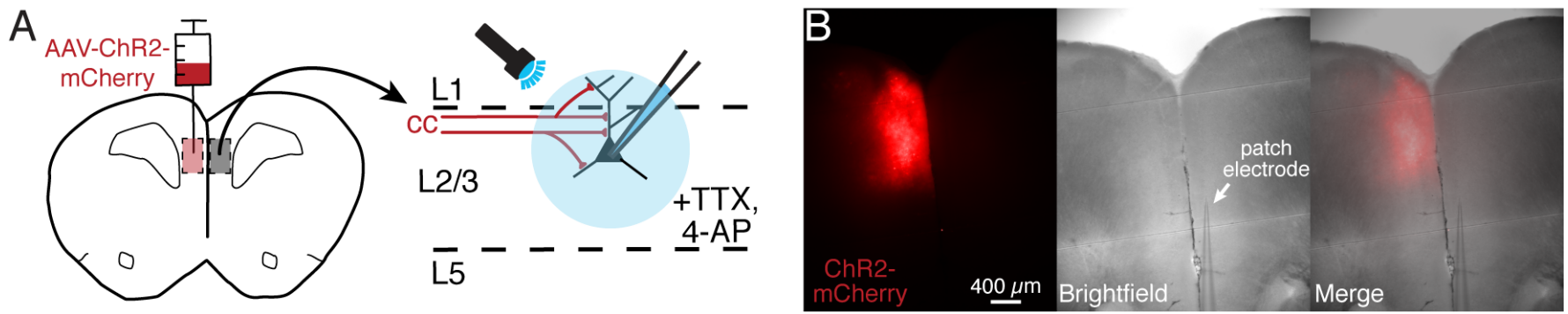

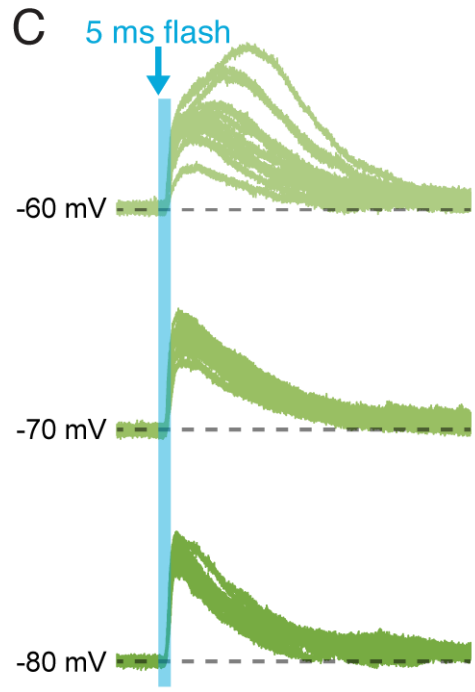

Both (baseline) $-80 \mathrm{mV}$ - $-60 \mathrm{mV}$
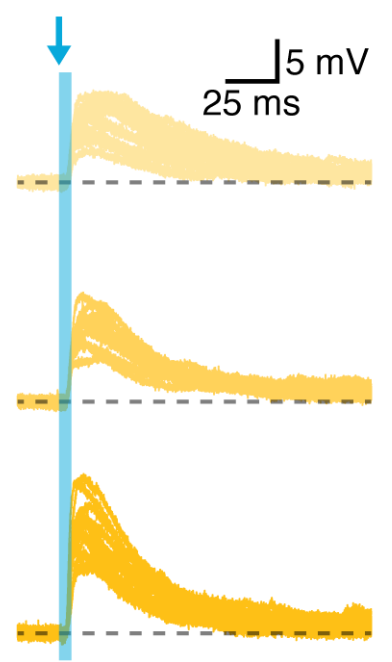

AMPA $(50 \mu \mathrm{M}$ AP5) $-80 \mathrm{mV}--60 \mathrm{mV}$
$\mathrm{D}$
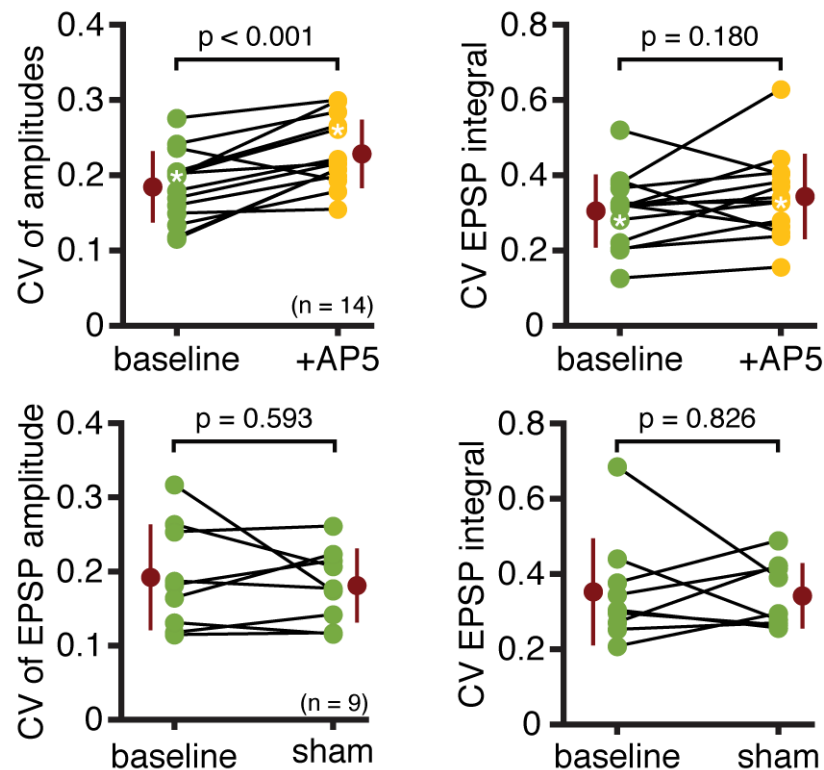

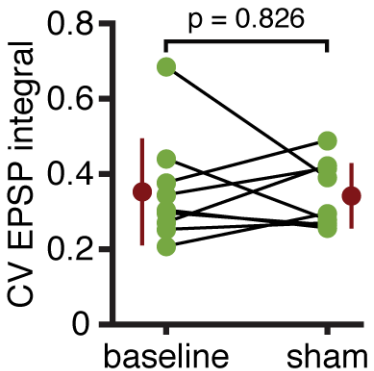

Figure 6. Blocking NMDA receptors increases the variability of distributed excitatory synaptic inputs in cortical pyramidal neurons.

$\boldsymbol{A}$, Schematic of experimental setup, in which an AAV encoding channelrhodopsin-2 tagged with mCherry is injected into one cortical hemisphere (left) to allow subsequent optical activation of callosal afferents while recording from layer 2/3 pyramidal neurons in the opposite hemisphere (right). $\boldsymbol{B}$, Low power (2.5x) epifluorescent (left) and brightfield (middle) images of the mPFC showing mCherry expression in one hemisphere and the recording electrode in the other. Superimposed images (overlaid epifluorescence image is set to $33 \%$ opacity) shown at right. $\boldsymbol{C}$, Fifteen consecutive EPSPs in response to 5 ms flashes of blue light (arrows) in a layer 2/3 pyramidal neuron held at three different membrane potentials (via somatic current injection) before (green) and after (yellow) blockade of NMDA receptors with $50 \mu \mathrm{M}$ AP5. EPSPs were collected in the presence of $1 \mu \mathrm{M}$ TTX and $100 \mu \mathrm{M} 4-\mathrm{AP}$. D. Plots of CVs for amplitudes (left) and integrals (right), calculated across all initial membrane potentials, in baseline conditions and after application of AP5 (top; $n=14$ ), or in sham experiments in which no AP5 was delivered (bottom; $n=9$ ). Means

Across all membrane potentials, the mean CVs for EPSP amplitude increased following blockade of NMDA receptors (by $28 \pm 27 \%$, from $0.18 \pm 0.05$ in baseline conditions to $0.23 \pm 0.05$ in AP5; $n=14 ; p$ $<0.001$; Figure 6D). This effect of AP5 could not be attributed to time-dependent changes in synaptic transmission, as no increase in mean CV was observed for amplitudes in control neurons given a "sham" application of non-drugged artificial cerebral spinal fluid (aCSF; mean change of 0 $\pm 24 \%$, from $0.19 \pm 0.07$ to $0.18 \pm 0.05 ; n=9 ; p=$ 0.448 ; Figure 6D). On the other hand, blockade of NMDA receptors with AP5 did not significantly increase the $\mathrm{CV}$ of integrals when calculated across all three holding potentials (mean change of $17 \pm 30 \%$ change, from $0.30 \pm 0.10$ in baseline conditions to $0.34 \pm 0.11$ in AP5; $p=0.180$; Figure 6D). This result was similar to results in neurons given a sham treatment (integral CVs were 0.35 \pm 0.14 in baseline conditions and $0.34 \pm 0.09$ after sham treatment; $p=0.826$; Figure 6D).

To further test the impact of NMDA conductance on EPSP-spike coupling, we simulated synaptic barrages in a reconstructed layer 5 pyramidal neuron (Stuart \& Spruston, 1998) fitted with spinous synaptic input at $10 \mu \mathrm{m}$ intervals across the entire dendritic tree (Figure 7A). For each of twenty trials, 1200 spines were randomly selected for synaptic input, and their timings of activation within a $360 \mathrm{~ms}$ window selected according to a uniform distribution. Each of the twenty synaptic barrages was repeated across 32 RMPs by setting 


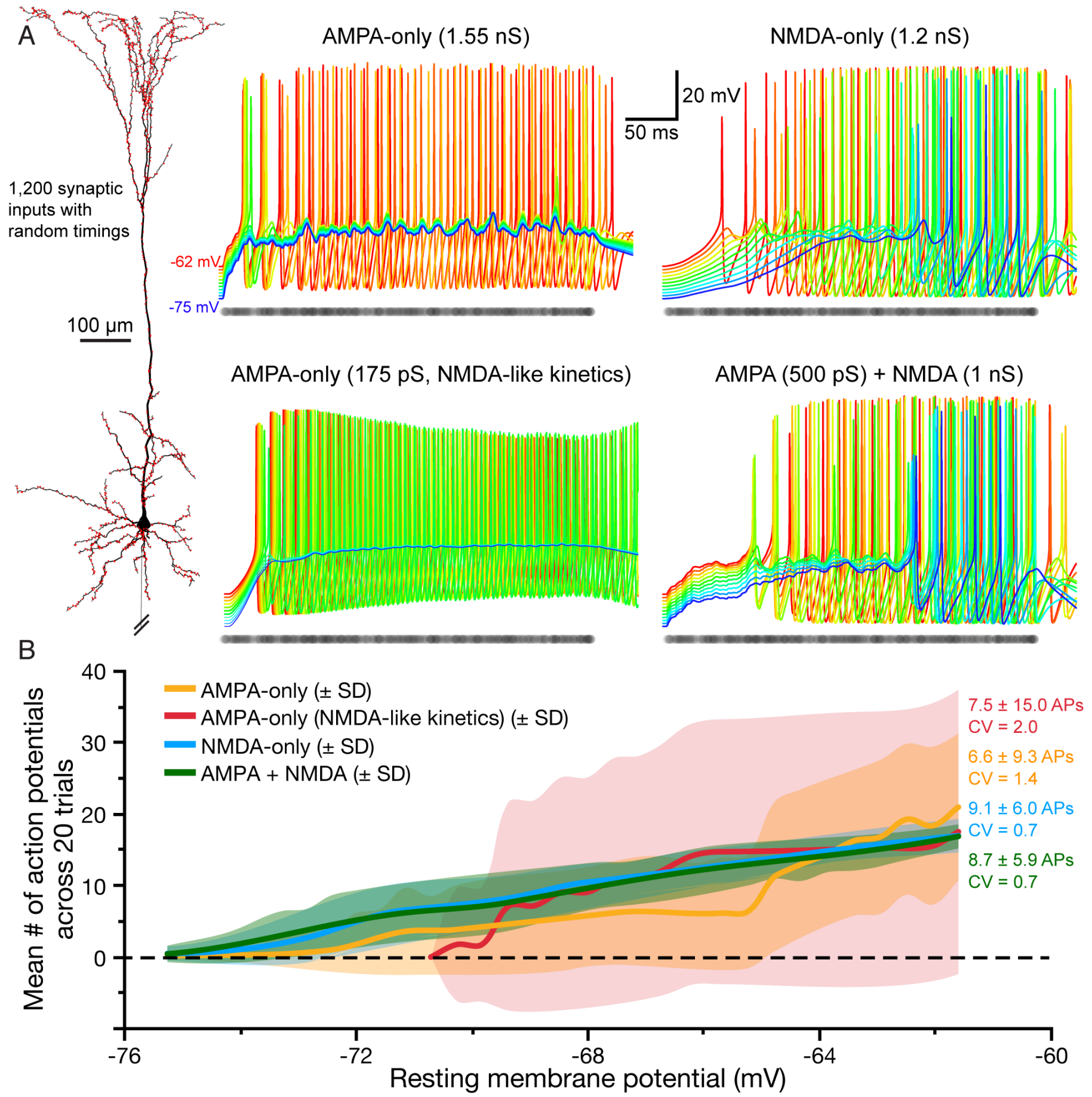

Figure 7. Voltage-dependence of the NMDA conductance improves the fidelity of EPSP-spike coupling.

$\boldsymbol{A}$, Synaptic inputs $(\mathrm{n}=3,961)$ were placed at $10 \mu \mathrm{m}$ intervals along the dendrites of a reconstructed layer 5 pyramidal neuron (left). For each of 20 trials, 1200 synapses were randomly selected and assigned timings of activation within a $360 \mathrm{~ms}$ window according to a uniform distribution. Shown are voltage responses measured at the soma in response to a single spatiotemporal pattern of synaptic input (activated spines enlarged and colored red in diagram, timing of synaptic activations shown in overlapping transparent grey markers below trace, such that darker areas indicate greater temporal density of synaptic input) generated across 32 different RMPs (11 shown for clarity of traces) set by adjusting the reversal potential for the passive conductance in all somatodendritic compartments to values between -59 and $-90 \mathrm{mV}$ (resulting in somatic membrane potentials ranging from -62 to $-75 \mathrm{mV}$ ). Synapses contained an AMPA-only conductance (1.5 nS, modified with 50 additional pS of an AMPA conductance with NMDAlike kinetics; upper left traces), the NMDA conductance alone (modified to $1.2 \mathrm{nS}$; upper right traces), a "slow" AMPA conductance with NMDA-like kinetics (175 pS; bottom left traces), and combined AMPA and NMDA conductances (500 pS and $1 \mathrm{nS}$, respectively; lower right traces). Conductances were modified so that each model generated a similar mean number of action potentials at the most depolarized RMP. Color indicates somatic RMP, from -62 mV (bright red) to $-75 \mathrm{mV}$ (dark blue). $\boldsymbol{B}$. Plot of the mean number of action potentials ( \pm standard deviation, shaded) generated across all 20 spatiotemporal patterns of synaptic input for each RMP. To the right are listed the mean action potential (AP) output and CV calculated across all trials and RMPs for each synaptic conductance (as indicated by color). 
bioRxiv preprint doi: https://doi.org/10.1101/566117; this version posted August 11,2019 . The copyright holder for this preprint (which was not certified by peer review) is the author/funder, who has granted bioRxiv a license to display the preprint in perpetuity. It is made available under aCC-BY-NC 4.0 International license.

Li et al., page 15

A

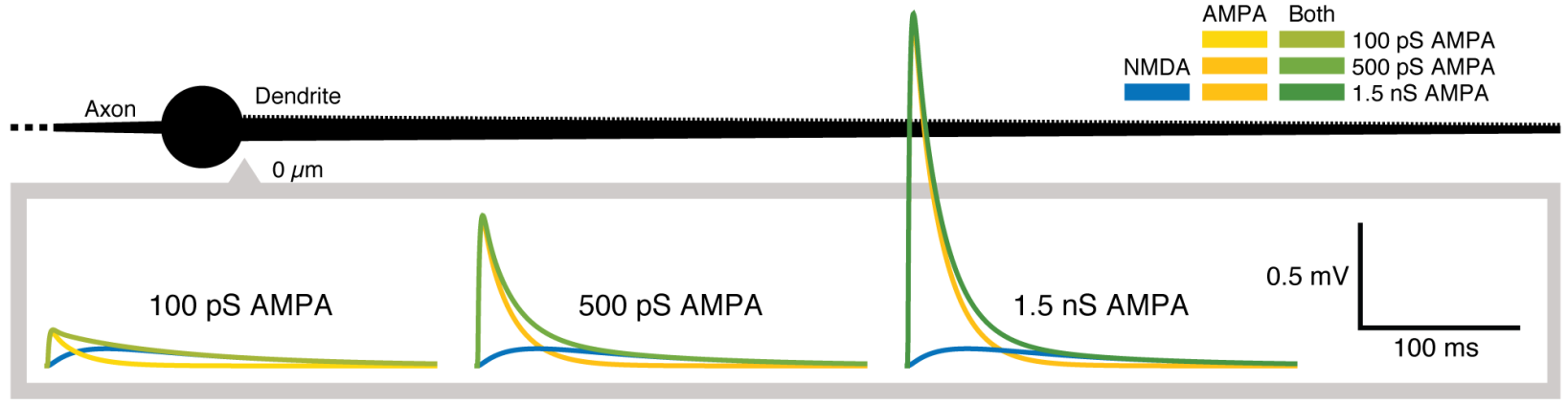

B

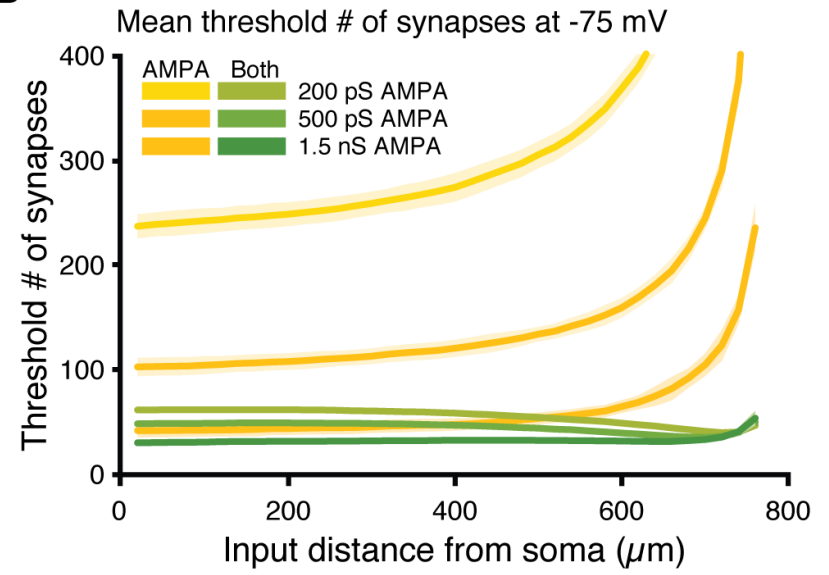

C

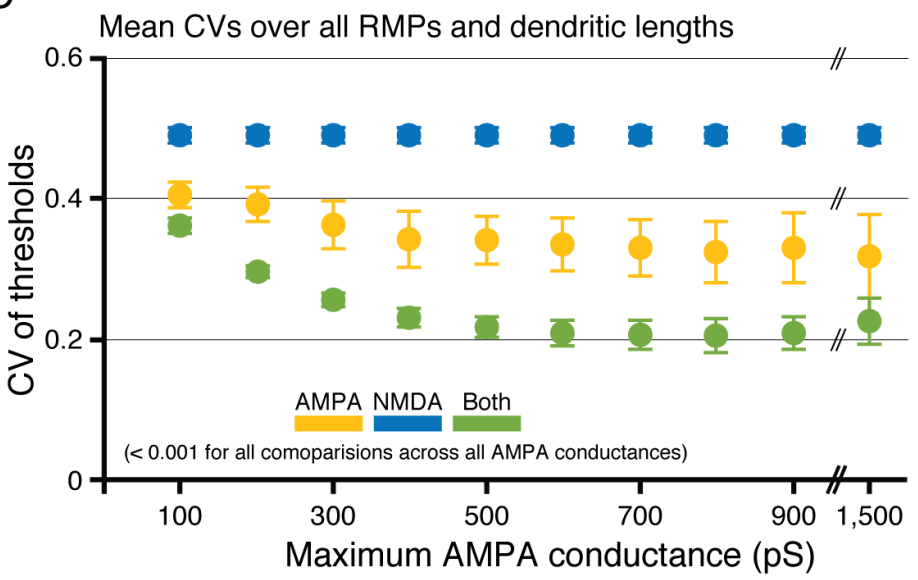

D
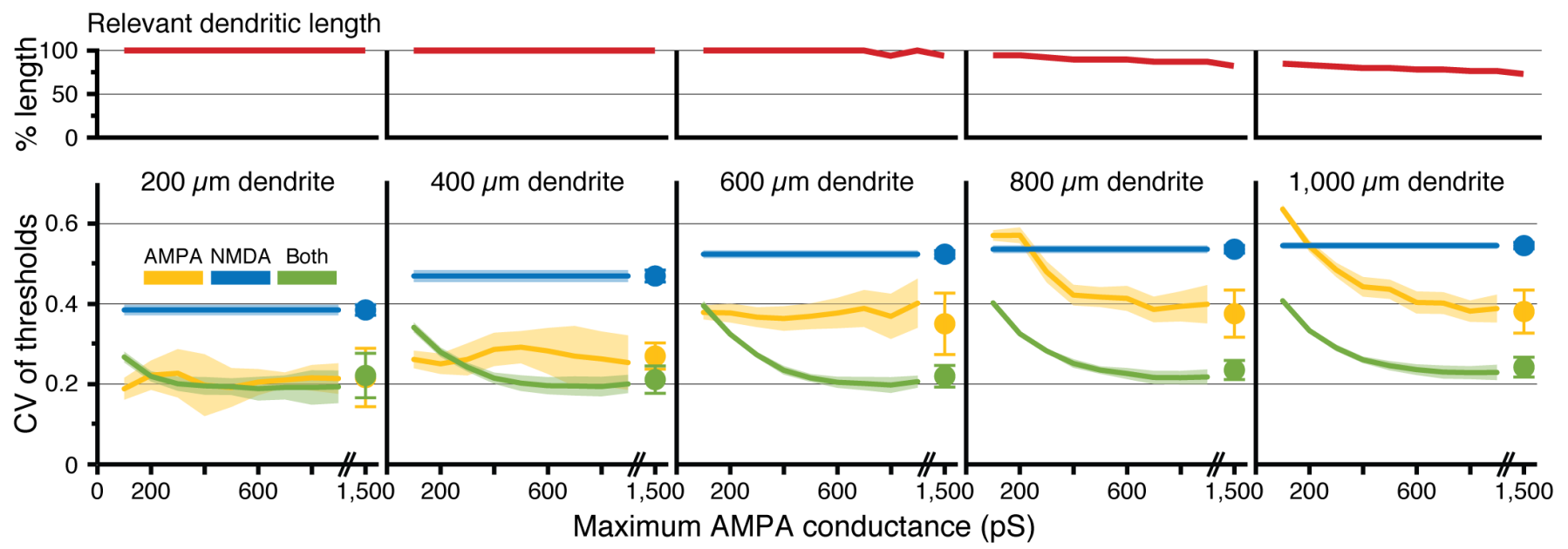

Figure 8. NMDA-dependent stabilization of EPSP-spike coupling occurs over a range of AMPA-to-NMDA conductance ratios.

$\boldsymbol{A}$, Somatic EPSPs generated by proximal inputs having the indicated maximum AMPA conductances (maximal NMDA conductance held steady at $1 \mathrm{nS}$ ) in a ball-and-stick neuron (black; not drawn to scale). $\boldsymbol{B}$, Plots of the mean number of synaptic activations necessary to fire an action potential in an $800-\mu \mathrm{m}$-long ball-and-stick neuron resting at $-75 \mathrm{mV}$ and having maximal AMPA conductance set to 200,500 , or $1,500 \mathrm{pS}$, either alone (yellow) or together with a $1 \mathrm{nS}$ NMDA conductance (green). $\boldsymbol{C}$. Plots of mean CVs ( \pm standard deviation) for the threshold numbers of synaptic activations necessary to drive action potential generation across all dendritic lengths and resting membrane potentials for the indicated maximal AMPA conductance. $\boldsymbol{D}$, Plots of mean CVs for thresholds $( \pm$ standard deviation; shaded region) for each dendritic length for inputs having only AMPA (yellow), or AMPA plus NMDA (green), conductances as a function of maximal AMPA conductance (0.1 to $1.5 \mathrm{nS}$ ). As a reference, the CV ( \pm standard deviation) for NMDA-only synapses is shown in blue. CVs were calculated across the relevant dendritic length (top; indicated as a percent of total length; see Methods).

the reversal potential for the passive conductance to values between -59 and $-90 \mathrm{mV}$ (actual somatic steady-state RMPs varied between -62 and -75 due to the presence of voltage-gated conductances throughout the neuron). When synapses contained both AMPA (500 pS) and NMDA (1 nS) conductances, synaptic barrages generated action potentials in at least some trials, across all RMPs, 
from a minimum of $0.5 \pm 1.1$ action potentials per trial (in four of twenty trials that were suprathreshold) at the most hyperpolarized RMP, to a maximum of $17.3 \pm 1.6$ action potentials per trial (all trials suprathreshold) at the most depolarized RMPs (Figure 7A, B). Similar results were observed when synapses contained only the NMDA conductance (enhanced to $1.2 \mathrm{nS}$; see Methods), with mean output varying from $0.5 \pm 1.0$ action potentials (five trials being suprathreshold) at the most hyperpolarized RMP, to $17 \pm 1.3$ action potentials (all trials suprathreshold) at the most depolarized RMP (Figure 7A, B). However, when synapses contained only AMPA-like conductances, action potential output was more variable across both trials and RMP. Since fast AMPA conductances, even at $2.5 \mathrm{nS}$ maximal conductance, failed to generate significant action potential output (mean of only $3.9 \pm 1.3$ action potentials per trial, across all RMPs; data not shown), we incorporated a 1.55 nS AMPA conductance, of which 50 pS had slow, NMDA-like kinetics (but no voltage-dependence). In this case, mean output across trials moved from $0.2 \pm 0.5$ action potentials per trial (with only two of twenty trials being suprathreshold) at the most hyperpolarized RMP, to $21.0 \pm 10.3$ action potentials per trial (with two of twenty trials failing to reach threshold) at the most depolarized RMP (Figure 7A, B). Similarly, when the entire AMPA conductance was given slow, NMDA-like kinetics paired with smaller maximum conductance (175 pS), all trials were subthreshold across the twelve most hyperpolarized RMPs, but increased to 17.6 \pm 19.9 action potentials at the most depolarized RMP, where output oscillated between zero action potentials (across eleven trials) and 38 or 40 action potentials (in the other nine trials; Figure 7A, B). Thus, the combined presence of synaptic AMPA and NMDA conductances stabilized EPSP-spike coupling across patterns of synaptic input (trials) and RMP.

Impact of AMPA-to-NMDA conductance ratios on synaptic integration

The results above reveal that the intrinsic voltage-dependence of the NMDA conductance can increase the fidelity of synaptic integration, as measured at the soma and axon, across dendritic locations and RMPs. However, while the number of synaptic NMDA receptors synapse is thought to be relatively uniform across most synapses (on the order of 10 receptors per synapse; Racca et al., 2000; Nimchinsky et al., 2004; Noguchi et al., 2005), synaptic AMPA conductances can range from zero (i.e., in "silent" synapses) to $>1.5$ nS (Beaulieu-Laroche \& Harnett, 2018), and are dynamic in response to synaptic plasticity (for review, see Herring \& Nicoll, 2016). Thus, the ratio of AMPA-to-NMDA conductance at synapses is variable. To determine the impact of AMPA-toNMDA ratio on the fidelity of synaptic integration, we varied the maximal AMPA conductance from 0.1 to $1.5 \mathrm{nS}$ while keeping the maximal NMDA conductance steady at $1 \mathrm{nS}$, and measured the number of synaptic activations necessary to generate an action potential in ball-and-stick neurons of various dendritic lengths (Figure 8). Regardless of AMPA conductance magnitude, the threshold number of synaptic inputs for action potential initiation increased sharply with distance from the soma for AMPA-only inputs, while thresholds for inputs containing both AMPA and NMDA conductances were relatively independent of distance (Figure 8B). In long dendrites (> 400 $\mu \mathrm{m})$ the mean $\mathrm{CV}$ for the threshold number of inputs was lowest when both conductances were present, regardless of AMPA-to-NMDA ratio (Figure 8D). In ball-and-stick model neurons with short dendrites, and especially when AMPA conductances were small, adding an NMDA conductance did not significantly reduce threshold CVs, as the NMDA conductance became the dominant driver of somatic depolarization, and CVs converged with those of NMDA-only inputs. This is likely due to the tight electrotonic structure of small model neurons, as adding additional dendrites to the soma and/or to the main dendritic branch preserved the stabilization of EPSP inputs even in short $(\sim 200 \mu \mathrm{m})$ dendrites (not shown; but compare also results from the small-but-branched dentate granule neuron in Figure 4). Thus, the voltagedependence of the NMDA conductance enhanced the fidelity of synaptic integration across dendritic location and RMP across a wide range of physiologically relevant AMPA-to-NMDA ratios.

\section{Discussion}

Synaptic integration, the process by which patterns of synaptic input are transduced into action potential initiation (also known as "EPSPspike coupling"), is the core of neural computation. We tested the impact of two prominent and often co-expressed glutamate receptor subtypes, AMPA and NMDA receptors, on the fidelity of synaptic integration across dendritic location and neuronal state (i.e., initial membrane potential). Our results demonstrate that the voltage-dependence of the NMDA conductance acts as a counterbalance of distance-dependent signal attenuation and reduced synaptic driving forces occurring at depolarized membrane potentials (as summarized in Figure 9), and can effectively increase the fidelity of EPSP- 


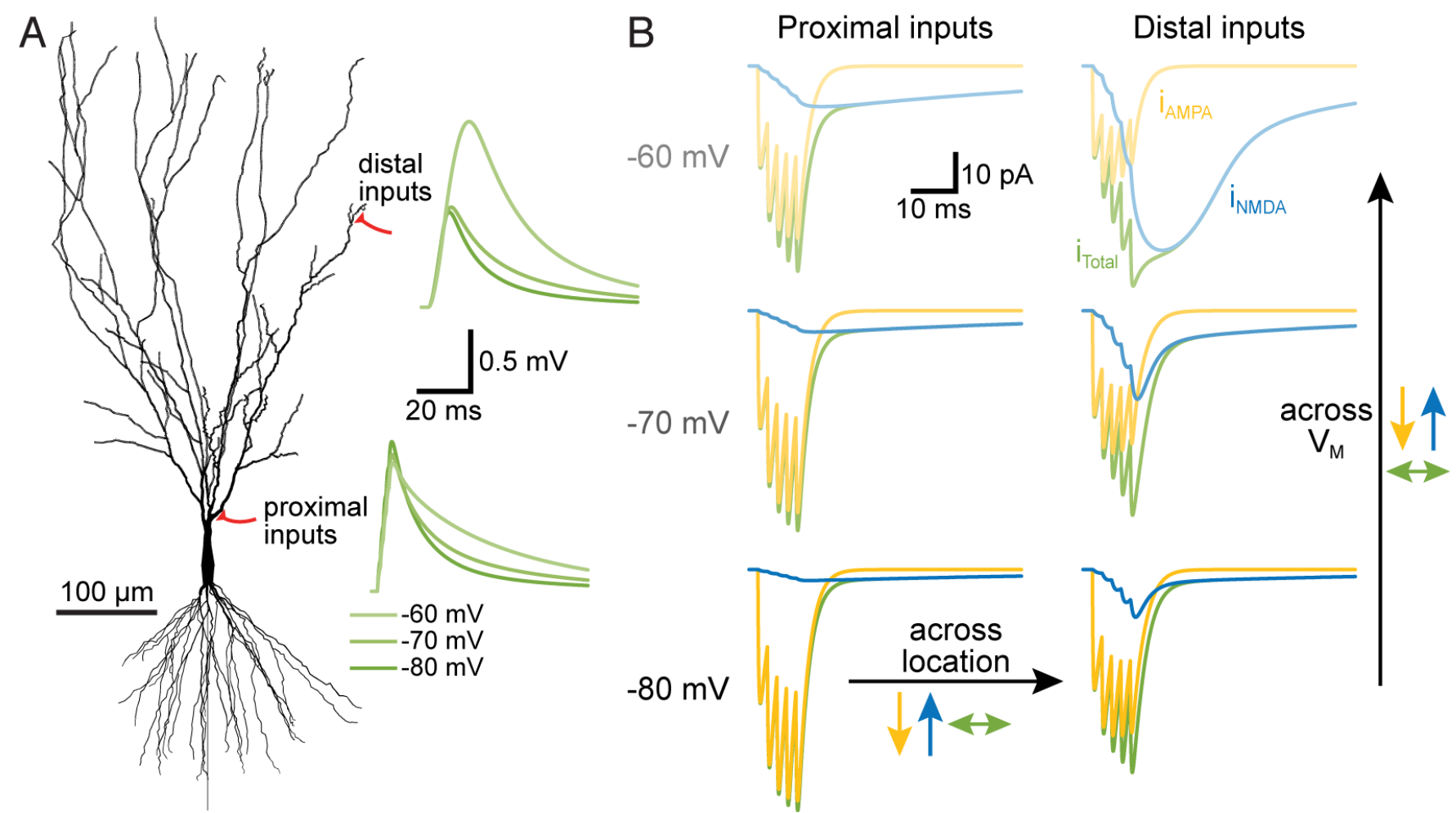

Figure 9. Mechanism of NMDA-dependent stabilization of synaptic integration across dendritic location and RMP.

$\boldsymbol{A}$, Shown are the morphology of a CA3 neuron showing the locations of proximal and distal inputs to the apical dendrite (five AMPA+NMDA synapses at neighboring spines at each location, timed to activate at 2 ms intervals) and the somatic responses to activation of those inputs at three different RMPs (green traces; RMP indicated by colordepth). B, Synaptic currents generated by activation of proximal (left) and distal (right) inputs at three RMPs. Total synaptic currents (i i $o t a l)$ are shown in green, with the AMPA (iAMPA; yellow) and NMDA (inMDA; blue) components superimposed. Notice that AMPA currents are reduced (yellow arrows), while NMDA as currents are enhanced (blue arrows), as inputs are moved from proximal to distal locations, or as RMP is depolarized. These opposing effects of location and RMP limits the variability of the total synaptic current across location and/or RMP (green arrows).

spike coupling at the axon. This consequence of synaptic NMDA receptors occurs over a broad range of AMPA-to-NMDA conductance ratios, and is independent of, but fully compatible with, its well characterized role in gating synaptic plasticity.

\section{Interaction of electrotonic structure and synaptic conductance}

EPSPs are shaped by the electrotonic structure of the dendritic tree; in narrow distal dendrites, small surface areas limit local membrane conductance and capacitance, yielding greater input impedance and larger and faster local EPSPs in response to synaptic currents (Gulledge et al., 2005). This can lead to reduced synaptic current in distal dendrites, as greater local depolarization during the EPSP reduces the driving force for the underlying synaptic conductance. At the same time, dendrites act as low-pass filters for EPSPs spreading from the site of synaptic input toward the soma. Thus, the somatic efficacy of synaptic input diminishes with distance from the soma, leading to higher threshold numbers of synaptic inputs to reach action potential threshold (see Figures 1-3 and 8). Our results demonstrate that NMDA receptors, via their intrinsic voltage-dependence, reduce location-dependent variability in synaptic efficacy by boosting synaptic currents preferentially in high-impedance dendritic compartments (Branco \& Hausser, 2011; Gulledge et al., 2012) and/or when neurons are in depolarized states (Branco et al., 2010), conditions in which synaptic driving forces are diminished (Figure 9). NMDAdependent stabilization of synaptic integration was robust across neuron morphologies and over a wide range of AMPA-to-NMDA conductance ratios, and was enhanced by active properties in dendrites (see Figure 2C) that contribute to voltagedependent amplification of inward current following synaptic activation (Magee \& Johnston, 1995; Lipowsky et al., 1996; Branco et al., 2010).

In both simulated and live neurons, the combined availability of NMDA and AMPA conductances reduced variability of EPSPs for simultaneously activated, but spatially distributed, synaptic input. As evident in Figure 5C, changes in 
membrane potential have opposing effects on AMPA-only and NMDA-only somatic EPSP amplitudes and integrals, while combining both conductances stabilizes responses across pattern of synaptic input and RMP. In our whole-cell recordings of neocortical neurons, blockade of NMDA receptors increased the variability of somatic EPSP amplitudes and integrals when EPSPs were generated from fairly hyperpolarized membrane potentials (-80 to $-70 \mathrm{mV}$ ). At our most depolarized potential $(-60 \mathrm{mV})$, EPSPs were already quite variable in baseline conditions (see Figure 6C), likely reflecting stochastic initiation of NMDA spikes in highly depolarized dendritic compartments. In addition, non-synaptic voltageactivated conductances in dendrites make input impedance voltage-dependent (Surges et al., 2004; Day et al., 2005). Thus, while reduced driving forces at depolarized membrane potentials tends to generate smaller AMPA-only EPSP amplitudes and integrals in simulated passive neurons (see Figure $5 B$ ), the presence of active conductances in real neurons will influence input impedance at depolarized membrane potentials, complicating predictions of how voltage will impact EPSP amplitudes and integrals in living neurons. Still, in spite of this biological variability, blockade of NMDA receptors in vitro increased the CVs of optogenetically evoked EPSP amplitudes and integrals, supporting a role for NMDA receptors in stabilizing synaptic integration across a range of subthreshold membrane potential states.

Impact of NMDA conductance on synaptic integration and network performance

Neurons employ a variety of mechanisms to combat location-dependent variability in synaptic efficacy. In the apical dendrites of CA1 pyramidal neurons, synaptic conductance is scaled in proportion to distance from the soma to minimize location-dependent variability of axonal drive (Magee \& Cook, 2000; Nicholson et al., 2006; Shipman et al., 2013). Alternatively, dendrites may express dendritic voltage-gated sodium and calcium conductances that, with sufficient local depolarization, can generate dendritic action potentials that amplify somatic EPSPs (e.g., Magee et al., 1995; Magee \& Johnston, 1995; Schiller et al., 1997; Golding \& Spruston, 1998; Golding et al., 1999; Milojkovic et al., 2005). Similarly, synaptic NMDA receptors, when activated in sufficient numbers, generate self-sustaining plateau potentials ("NMDA spikes") that lead to supralinear synaptic summation and larger somatic EPSPs (Schiller et al., 2000; Wei et al., 2001; Polsky et al., 2004; Nevian et al., 2007; Major et al., 2008; Larkum et al., 2009; Branco et al., 2010; Branco \&
Hausser, 2011; Harnett et al., 2012). These voltage-dependent synaptic and dendritic mechanisms act preferentially in distal dendritic compartments, where input impedance is highest, and facilitate synaptic depolarization of the soma and axon in spite of distance-dependent voltageattenuation within the dendritic arbor. However, unlike action potentials, NMDA spikes are not allor-none. Instead, they vary in amplitude and duration in proportion to the number of activated synapses, the local input impedance at the synapse, and the initial membrane potential (Major et al., 2008; Branco et al., 2010; Branco \& Hausser, 2011; Gulledge et al., 2012; Farinella et al., 2014). Thus, although highly nonlinear across voltage, NMDA spikes are effectively "graded" in amplitude and duration across dendritic locations (see Figure 2B), allowing the NMDA conductance to enhance synaptic current in proportion to electrotonic distance from the soma and axon. Similarly, by opposing the impact of reduced synaptic driving force on AMPA-mediated currents, voltagedependent NMDA conductances can reduce the variability of total synaptic current during temporal integration of clustered excitatory inputs (Connelly et al., 2016; see also Figure 9).

Over the past several decades, there has been growing appreciation that, in addition to gating many forms of synaptic plasticity, NMDA receptors play an integral role in normal synaptic integration (for reviews, see Hausser \& Mel, 2003; Antic et al., 2010; Major et al., 2013). In the distal apical tufts of layer 5 neurons, where high input impedance favors amplification of local EPSPs, NMDA activation boosts synaptic currents such that they can more reliably trigger calcium spikes at an electrically excitable zone at the base of the tuft (Larkum et al., 2009). Indeed, simulations by Larkum et al. (2009) found the threshold number of synapses necessary for initiating an apical trunk calcium spike to be relatively consistent across tuft locations when NMDA conductances were present, but that thresholds for AMPA-only inputs grew exponentially, and to non-physiological synaptic densities, with distance from the initiation zone in the apical dendrite. Thus, the impact of NMDA receptors on the fidelity of EPSP-spike coupling may not be limited to axonal action potentials, but likely applies more generally for spike initiation at any specialized trigger zone, as long as it is electrotonically downstream (e.g., in a larger compartment) from the site of synaptic input.

The importance of NMDA receptors to normal synaptic integration can be inferred from the cognitive impairments produced by acute NMDA receptor blockade in animals and humans. For instance, sub-anesthetic doses of ketamine impair 
executive function, including working memory, in primates (Taffe et al., 2002; Condy et al., 2005; Stoet \& Snyder, 2006; Blackman et al., 2013; Skoblenick \& Everling, 2014) and humans (Krystal et al., 1994; Adler et al., 1998; Hetem et al., 2000), and these cognitive effects are directly attributable to ketamine's antagonism of NMDA receptors (Shaffer et al., 2014; Ma et al., 2015). We propose that these acute effects of NMDA receptor blockade may result from reduced fidelity of synaptic integration, particularly in neurons with large, electrotonically diverse dendritic trees.

\section{Conclusions}

Transduction of synaptic events into patterns of action potential output is the most fundamental neuronal task. It is a process influenced by the strength and kinetics of individual synaptic conductances, the spatiotemporal relationships among them, and the electrotonic properties of the neuron. Nonlinear amplification of synaptic input via NMDA spikes is proposed to increase the "computational power" of neurons (e.g., Wei et al., 2001; Poirazi et al., 2003; Branco \& Hausser, 2011). Our results demonstrate that NMDA receptors, via their intrinsic voltage dependence, also provide the advantage of "computational stability" by enhancing the fidelity of EPSP-spike coupling across dendritic domains and membrane potential states. dWhile speculative, it is interesting to consider whether this consequence of NMDA receptor expression may have provided advantages to primitive nervous systems (e.g., in cnidaria; Anctil, 2009; Pierobon, 2012) independent of their role in associative plasticity, which may account for their ancient evolutionary origin in the common ancestor of all metazoans (RamosVicente et al., 2018).

\section{References}

Adler CM, Goldberg TE, Malhotra AK, Pickar D \& Breier A. (1998). Effects of ketamine on thought disorder, working memory, and semantic memory in healthy volunteers. Biol Psychiatry 43, 811-816.

Anctil M. (2009). Chemical transmission in the sea anemone Nematostella vectensis: A genomic perspective. Comp Biochem Physiol Part D Genomics Proteomics 4, 268-289.

Antic SD, Zhou WL, Moore AR, Short SM \& Ikonomu KD. (2010). The decade of the dendritic NMDA spike. J Neurosci Res 88, 2991-3001.

Beaulieu-Laroche L \& Harnett MT. (2018). Dendritic Spines Prevent Synaptic Voltage Clamp. Neuron 97, 75-82 e73.
Blackman RK, Macdonald AW, 3rd \& Chafee MV. (2013). Effects of ketamine on context-processing performance in monkeys: a new animal model of cognitive deficits in schizophrenia. Neuropsychopharmacology 38, 2090-2100.

Branco T, Clark BA \& Hausser M. (2010). Dendritic discrimination of temporal input sequences in cortical neurons. Science 329, 1671-1675.

Branco T \& Hausser M. (2010). The single dendritic branch as a fundamental functional unit in the nervous system. Curr Opin Neurobiol 20, 494-502.

Branco T \& Hausser M. (2011). Synaptic integration gradients in single cortical pyramidal cell dendrites. Neuron 69, 885-892.

Carnevale NT \& Hines ML. (2006). The NEURON Book. Cambridge University Press, New York.

Cash S \& Yuste R. (1998). Input summation by cultured pyramidal neurons is linear and position-independent. J Neurosci 18, 10-15.

Cichon J \& Gan WB. (2015). Branch-specific dendritic $\mathrm{Ca}(2+)$ spikes cause persistent synaptic plasticity. Nature 520, 180-185.

Condy C, Wattiez N, Rivaud-Pechoux S \& Gaymard B. (2005). Ketamine-induced distractibility: An oculomotor study in monkeys. Biol Psychiatry 57, 366-372.

Connelly WM, Crunelli V \& Errington AC. (2016). Passive Synaptic Normalization and Input SynchronyDependent Amplification of Cortical Feedback in Thalamocortical Neuron Dendrites. J Neurosci 36, 3735-3754.

Day M, Carr DB, Ulrich S, Ilijic E, Tkatch T \& Surmeier DJ. (2005). Dendritic excitability of mouse frontal cortex pyramidal neurons is shaped by the interaction among HCN, Kir2, and Kleak channels. J Neurosci 25, 8776-8787.

Diamond JS \& Copenhagen DR. (1993). The contribution of NMDA and non-NMDA receptors to the light-evoked input-output characteristics of retinal ganglion cells. Neuron 11, 725-738.

Farinella M, Ruedt DT, Gleeson P, Lanore F \& Silver RA. (2014). Glutamate-bound NMDARs arising from in vivo-like network activity extend spatio-temporal integration in a L5 cortical pyramidal cell model. PLoS computational biology 10, e1003590.

Golding NL, Jung HY, Mickus T \& Spruston N. (1999). Dendritic calcium spike initiation and repolarization are controlled by distinct potassium channel subtypes in CA1 pyramidal neurons. J Neurosci 19, 8789-8798. 
Golding NL \& Spruston N. (1998). Dendritic sodium spikes are variable triggers of axonal action potentials in hippocampal CA1 pyramidal neurons. Neuron 21, 1189-1200.

Greer JB, Khuri S \& Fieber LA. (2017). Phylogenetic analysis of ionotropic L-glutamate receptor genes in the Bilateria, with special notes on Aplysia californica. BMC Evol Biol 17, 11.

Grienberger C, Chen X \& Konnerth A. (2014). NMDA receptor-dependent multidendrite $\mathrm{Ca}(2+)$ spikes required for hippocampal burst firing in vivo. Neuron 81, 1274-1281.

Grienberger C, Chen X \& Konnerth A. (2015). Dendritic function in vivo. Trends Neurosci 38, 45-54.

Grundy D. (2015). Principles and standards for reporting animal experiments in The Journal of Physiology and Experimental Physiology. J Physiol 593, 2547-2549.

Gulledge AT, Carnevale NT \& Stuart GJ. (2012). Electrical advantages of dendritic spines. PloS one 7, e36007.

Gulledge AT, Kampa BM \& Stuart GJ. (2005). Synaptic integration in dendritic trees. J Neurobiol 64, 75-90.

Harnett MT, Makara JK, Spruston N, Kath WL \& Magee JC. (2012). Synaptic amplification by dendritic spines enhances input cooperativity. Nature 491, 599-602.

Hausser M \& Mel B. (2003). Dendrites: bug or feature? Curr Opin Neurobiol 13, 372-383.

Hemond P, Migliore M, Ascoli GA \& Jaffe DB. (2009). The membrane response of hippocampal CA3b pyramidal neurons near rest: Heterogeneity of passive properties and the contribution of hyperpolarization-activated currents. Neuroscience 160, 359-370.

Herring BE \& Nicoll RA. (2016). Long-Term Potentiation: From CaMKII to AMPA Receptor Trafficking. Annu Rev Physiol 78, 351-365.

Hetem LA, Danion JM, Diemunsch P \& Brandt C. (2000). Effect of a subanesthetic dose of ketamine on memory and conscious awareness in healthy volunteers. Psychopharmacology (Berl) 152, 283-288.

lacobucci GJ \& Popescu GK. (2017). NMDA receptors: linking physiological output to biophysical operation. Nat Rev Neurosci 18, 236-249.

Jaffe DB \& Carnevale NT. (1999). Passive normalization of synaptic integration influenced by dendritic architecture. J Neurophysiol 82, 3268-3285.

Krystal JH, Karper LP, Seibyl JP, Freeman GK, Delaney R, Bremner JD, Heninger GR, Bowers MB, Jr. \& Charney DS. (1994). Subanesthetic effects of the noncompetitive NMDA antagonist, ketamine, in humans. Psychotomimetic, perceptual, cognitive, and neuroendocrine responses. Arch Gen Psychiatry 51, 199-214.

Larkum ME, Nevian T, Sandler M, Polsky A \& Schiller J. (2009). Synaptic integration in tuft dendrites of layer 5 pyramidal neurons: a new unifying principle. Science 325, 756-760.

Lipowsky R, Gillessen T \& Alzheimer C. (1996). Dendritic $\mathrm{Na}+$ channels amplify EPSPs in hippocampal CA1 pyramidal cells. J Neurophysiol 76, 2181-2191.

Luscher C \& Malenka RC. (2012). NMDA receptordependent long-term potentiation and long-term depression (LTP/LTD). Cold Spring Harb Perspect Biol 4.

Ma L, Skoblenick K, Seamans JK \& Everling S. (2015). Ketamine-Induced Changes in the Signal and Noise of Rule Representation in Working Memory by Lateral Prefrontal Neurons. J Neurosci 35, 11612-11622.

Magee JC, Christofi G, Miyakawa H, Christie B, LasserRoss N \& Johnston D. (1995). Subthreshold synaptic activation of voltage-gated $\mathrm{Ca} 2+$ channels mediates a localized $\mathrm{Ca} 2+$ influx into the dendrites of hippocampal pyramidal neurons. J Neurophysiol 74, 1335-1342.

Magee JC \& Cook EP. (2000). Somatic EPSP amplitude is independent of synapse location in hippocampal pyramidal neurons. Nat Neurosci 3, 895-903.

Magee JC \& Johnston D. (1995). Synaptic activation of voltage-gated channels in the dendrites of hippocampal pyramidal neurons. Science 268, 301-304.

Major G, Larkum ME \& Schiller J. (2013). Active properties of neocortical pyramidal neuron dendrites. Annu Rev Neurosci 36, 1-24.

Major G, Polsky A, Denk W, Schiller J \& Tank DW. (2008). Spatiotemporally graded NMDA spike/plateau potentials in basal dendrites of neocortical pyramidal neurons. J Neurophysiol 99, 2584-2601.

Milojkovic BA, Wuskell JP, Loew LM \& Antic SD. (2005). Initiation of sodium spikelets in basal dendrites of neocortical pyramidal neurons. J Membr Biol 208, 155-169.

Nevian T, Larkum ME, Polsky A \& Schiller J. (2007). Properties of basal dendrites of layer 5 pyramidal neurons: a direct patch-clamp recording study. Nat Neurosci 10, 206-214.

Nicholson DA, Trana R, Katz Y, Kath WL, Spruston N \& Geinisman Y. (2006). Distance-dependent differences in synapse number and AMPA receptor expression in 
hippocampal CA1 pyramidal neurons. Neuron 50, 431-442.

Nimchinsky EA, Yasuda R, Oertner TG \& Svoboda K. (2004). The number of glutamate receptors opened by synaptic stimulation in single hippocampal spines. J Neurosci 24, 2054-2064.

Noguchi J, Matsuzaki M, Ellis-Davies GC \& Kasai $H$. (2005). Spine-neck geometry determines NMDA receptor-dependent $\mathrm{Ca} 2+$ signaling in dendrites. Neuron 46, 609-622.

Palmer LM, Shai AS, Reeve JE, Anderson HL, Paulsen O \& Larkum ME. (2014). NMDA spikes enhance action potential generation during sensory input. Nat Neurosci 17, 383-390.

Pierobon P. (2012). Coordinated modulation of cellular signaling through ligand-gated ion channels in Hydra vulgaris (Cnidaria, Hydrozoa). Int J Dev Biol 56, 551-565.

Poirazi P, Brannon T \& Mel BW. (2003). Pyramidal neuron as two-layer neural network. Neuron 37, 989-999.

Polsky A, Mel B \& Schiller J. (2009). Encoding and decoding bursts by NMDA spikes in basal dendrites of layer 5 pyramidal neurons. J Neurosci 29, 11891-11903.

Polsky A, Mel BW \& Schiller J. (2004). Computational subunits in thin dendrites of pyramidal cells. Nat Neurosci 7, 621-627.

Racca C, Stephenson FA, Streit P, Roberts JD \& Somogyi P. (2000). NMDA receptor content of synapses in stratum radiatum of the hippocampal CA1 area. J Neurosci 20, 2512-2522.

Ramos-Vicente D, Ji J, Gratacos-Batlle E, Gou G, ReigViader R, Luis J, Burguera D, Navas-Perez E, GarciaFernandez J, Fuentes-Prior P, Escriva H, Roher N, Soto D \& Bayes A. (2018). Metazoan evolution of glutamate receptors reveals unreported phylogenetic groups and divergent lineage-specific events. Elife 7.

Schiller J, Major G, Koester HJ \& Schiller Y. (2000). NMDA spikes in basal dendrites of cortical pyramidal neurons. Nature 404, 285-289.

Schiller J, Schiller Y, Stuart G \& Sakmann B. (1997). Calcium action potentials restricted to distal apical dendrites of rat neocortical pyramidal neurons. $J$ Physiol 505 ( Pt 3), 605-616.

Schmidt-Hieber C, Jonas P \& Bischofberger J. (2007). Subthreshold dendritic signal processing and coincidence detection in dentate gyrus granule cells. $J$ Neurosci 27, 8430-8441.
Shaffer CL, Osgood SM, Smith DL, Liu J \& Trapa PE. (2014). Enhancing ketamine translational pharmacology via receptor occupancy normalization. Neuropharmacology 86, 174-180.

Shipman SL, Herring BE, Suh YH, Roche KW \& Nicoll RA. (2013). Distance-dependent scaling of AMPARs is cell-autonomous and GluA2 dependent. $J$ Neurosci 33, $13312-13319$.

Sivagnanam S, Majumdar A, Yoshimoto K, Astakhov V, Bandrowski A, Martone ME \& Carnevale NT. (2013). Introducing the Neuroscience Gateway. In International Workshop on Science Gateways, ed. Kiss T. CEUR-WS.org, Zürich.

Skoblenick K \& Everling S. (2014). N-methyl-d-aspartate receptor antagonist ketamine impairs actionmonitoring activity in the prefrontal cortex. J Cogn Neurosci 26, 577-592.

Stern P, Edwards FA \& Sakmann B. (1992). Fast and slow components of unitary EPSCs on stellate cells elicited by focal stimulation in slices of rat visual cortex. J Physiol 449, 247-278.

Stoet G \& Snyder LH. (2006). Effects of the NMDA antagonist ketamine on task-switching performance: evidence for specific impairments of executive control. Neuropsychopharmacology 31, 1675-1681.

Stuart G \& Spruston N. (1998). Determinants of voltage attenuation in neocortical pyramidal neuron dendrites. J Neurosci 18, 3501-3510.

Surges R, Freiman TM \& Feuerstein TJ. (2004). Input resistance is voltage dependent due to activation of $\mathrm{Ih}$ channels in rat CA1 pyramidal cells. J Neurosci Res 76, 475-480.

Taffe MA, Davis SA, Gutierrez T \& Gold LH. (2002). Ketamine impairs multiple cognitive domains in rhesus monkeys. Drug Alcohol Depend 68, 175-187.

Wei DS, Mei YA, Bagal A, Kao JP, Thompson SM \& Tang CM. (2001). Compartmentalized and binary behavior of terminal dendrites in hippocampal pyramidal neurons. Science 293, 2272-2275.

Competing Interests: The authors affirm that they have no conflicts of interest.

Author Contributions: A.T.G. conceived the project. C.L. and A.T.G designed and performed experimental work and analyzed data. A.L.B performed experimental work. A.T.G. wrote the paper. All authors reviewed and edited the paper. 
bioRxiv preprint doi: https://doi.org/10.1101/566117; this version posted August 11, 2019. The copyright holder for this preprint (which was not certified by peer review) is the author/funder, who has granted bioRxiv a license to display the preprint in perpetuity. It is made available under aCC-BY-NC 4.0 International license.

Funding: This work was supported by a grant from the National Institute for Mental Health (R01 MH099054; A.T.G.), a Frank and Myra Weiser Scholar Award (A.T.G.), and support from the Kaminsky Fund for Undergraduate Research at Dartmouth College (C.L.).

Acknowledgements: The authors thank Saiko Ikeda for technical assistance, and Greg Stuart and Nik Dembrow for comments on the manuscript.
Note: This article was first published as a preprint: Li C, Baker AL, Gulledge AT (2019). NMDA receptors enhance the fidelity of synaptic integration. bioRxiv. https://.doi.org/10.1101/566117. 